\title{
EL ASEDIO DE MANILA (MAYO-AGOSTO 1898). «DIARIO DE LOS SUCESOS OCURRIDOS DURANTE LA GUERRA DE ESPAÑA CON LOS ESTADOS UNIDOS, 1898»1
}

POR

\author{
LUIS E. TOGORES SÁNCHEZ \\ Universidad San Pablo-CEU (Madrid)
}

La pérdida de Filipinas en 1898 tiene dos hitos, la batalla naval de Cavite y el subsiguiente asedio de Manila. Entre mayo y agosto de 1898 las fuerzas independentistas tagalas de Aguinaldo y los soldados norteamericanos del comodoro Dewey y el general Merrit sitiaron la capital de la colonia para finalmente rendirla el 13 de agosto tras un duro y largo asedio repleto de combates. El diario de un jesuita encontrado en los archivos de Roma, el cual narra día a día aquellos sucesos, nos permite reconstruir -contrastándolo con otra documentación existente- una de las claves históricas para comprender la derrota de España ante los Estados Unidos en el Pacífico.

\section{LOS HECHOS.}

La derrota de la escuadra española el primero de mayo frente a Manila, y la subsiguiente caída del arsenal y plaza de Cavite, había condenado de forma irremisible la suerte de España en Filipinas.

Las fuerzas que mandaban el comodoro Dewey habían logrado en sólo unas horas lo que en buena medida resultaba casi imposible de creer, sobre todo dado el escaso coste que había tenido que pagar, terminar con la capacidad ofensiva de la fuerzas navales españolas en el Pacífico. Además, Dewey había obtenido una base naval en

1 Quiero en primer lugar dar las gracias a mi amiga Cecilia Harrison por haberme facilitado el documento que constituye el núcleo y corazón de este trabajo. Sin ella éste no hubiese sido posible. 
Asia Oriental, fundamental para la suerte de la guerra naval en aquella parte del mundo, pues "hemos de considerar que, como sabía muy bien éste, todo lo que no fuera por su parte una completa victoria equivaldría a una derrota, pues ni tendría lugar alguno donde reparar sus averías, ni podría carbonear sus buques, ni podría retroceder cruzando el Pacífico para refugiarse en una base propia. Su única salvación sería pasar por la humillación de dejarse internar en un puerto neutral"2.

A pesar de la terrible derrota de Cavite al capitán general del archipiélago, D. Basilio Augustín, aún le quedaban algunas bazas por jugar. Como muy bien comprendían los peninsulares, tanto civiles como militares, la soberanía española estaba segura siempre y cuando la población nativa del archipiélago se mantuviese fiel y dispuesta a luchar en favor de España. Los sucesos de 1896/97 hacían temer todo lo contrario y, a pesar del esfuerzo que hizo Augustín de ganarse a los tagalos y otros grupos de población de las islas -creación de una Asamblea Consultiva, promesas de concesión de la autonomía, creación de una milicia nativa, etc.-, la llegada de Aguinaldo, traído por el vapor norteamericano «MacCulloch» a Cavite, rompió desde casi el primer momento este espejismo.

España sólo podía contar con sus propias fuerzas, esencialmente con las tropas peninsulares de guarnición en el archipiélago y los escasos refuerzos que entre la población blanca y algunos nativos fieles se pudiesen reclutar deprisa y corriendo ${ }^{3}$. Junto a los recursos existentes en Asia, España sólo disponía de la Escuadra de Reserva, mandada por el almirante Cámara, anclada en la Península, la cual con su sola llegada a las Filipinas hubiese inclinado de forma ineludible la suerte de la guerra en el Pacífico a su favor.

Manila contaba para su defensa con unos efectivos muy reducidos, así como unas defensas obsoletas e ineficaces para la guerra que se avecinaba, o demasiado débiles dado la premura con que se habían construido.

Existía el viejo recinto amurallado construido a lo largo de varios siglos de colonización, muy efectivo para repeler ataques de los pi-

\footnotetext{
2 Agustín R., Rodríguez, La Guerra del 98. Las campañas de Cuba, Puerto Rico y Filipinas, Madrid, Agualarga, 1998, p. 120.

3 No olvidemos que el año y medio que había durado la pasada insurrección tagala hacía que estos paisanos fueran una fuerza relativamente curtida y disciplinada.
} 
ratas o defender el corazón de la ciudad de pequeñas revueltas nativas, pero anticuado y escasamente efectivo ante un asedio y subsiguiente asalto por fuerzas numerosísimas y dotadas de armamento moderno. Igual ocurría con los viejos fuertes y bastiones extramuros los cuales tendrían que resistir el inevitable ataque de los grandes cañones navales de la escuadra de Dewey y de la artillería moderna de los sitiadores.

Ante la inevitable guerra con Estados Unidos, el capitán general Primo de Rivera ordenó la construcción de 15 blocaos, situados unos de otros a unos 1.000 metros, con capacidad para 25 o 30 hombres, así como el de una sencilla pero práctica línea de trincheras, con la finalidad de crear un perímetro defensivo para los barrios situados fuera de la ciudad amurallada, ante un posible - mejor inevitable - asalto por tierra. Junto a estas medidas defensivas se procedió a la instalación de la escasa artillería de cierto calibre con que contaba el arsenal de la plaza. A este respecto cuenta el propio Primo de Rivera:

"El asunto de la defensa de la plaza se hacía muy complejo, por la probable eventualidad de que la presencia de la escuadra norteamericana pudiera coincidir con un movimiento insurreccional en la misma capital ó en los pueblos próximos. (...) Las fuerzas que guarnecen Manila se consideraron suficientes para atender á sofocar algún movimiento que estallase en la ciudad, pero no en los pueblos próximos si, levantados éstos, venían sobre la capital.

Era, pues, de necesidad urgente guardar todas las avenidas, y para conseguirlo se acordó la construcción de un número de fuertes que, situados en puntos estratégicos del perímetro de la capital, detuvieran la marcha de las masas que á ella pudieran dirigirse. Dispuse que una comisión presidida por el Comandante general de ingenieros, y compuesta de jefes de ingenieros y de estado mayor, procediese inmediatamente á la elección de los puntos donde debieran situarse los fuertes, ordenando, una vez elegido, empezaran las obras inmediatamente...

(...) La comisión nombrada para la elección de emplazamiento de los blockhaus, recorrió los alrededores de Manila en la tarde del 15 y mañana del 16 trayéndome, en la tarde de este día, un croquis detallado de construcción en la mañana del día 17..."4.

\footnotetext{
4 Fernando PRIMO DE RIVERA, Memoria dirigida al Senado por el capitán general D. Fernando Primo de Rivera y Sobremonte acerca de su gestión en Filipinas, Madrid, Imprenta y Litografía del Depósito de Guerra, 1898, pp. 184 y 185. En este escrito se encuentra una minuciosa descripción de los preparativos llevados adelante en el archipiélago ante la previsible guerra con los Estados Unidos.
} 
Desde el mismo momento en que se produjo la derrota naval de las fuerzas de Montojo, ante los ojos de la guarnición y población de Manila, incapaz de socorrer a la escuadra y guarnición de Cavite, la suerte de la ciudad estaba echada. Las fuerzas españolas diseminadas por Luzón, y por todo el archipiélago, formando minúsculas guarniciones, fueron incapaces de agruparse en columnas de cierta entidad para proceder a una defensa eficaz y luego concentrarse en Manila. Muchas de estas guarniciones eran muy pequeñas, recordemos el escaso medio centenar de hombres que formaba la de Baler, siendo por lo tanto casi inoperativas ${ }^{5}$. Los grupos más numerosos - columnas del general Peña, de Monet, del teniente coronel Albertí6 - intentaron dirigirse a Manila, pero sus relativamente escasos efectivos, lo duro del terreno, unido a la resistencia encarnizada de las partidas nativas, cada día más numerosas y mejor armadas, impidieron que estas fuerzas pudieran llegar y concentrarse en la capital de la colonia.

A esta situación se sumó la progresiva y continua deserción de la fuerzas nativas que se habían alistado en las milicias que con motivo de la guerra habían sido creadas, así como de unidades completas de nativos del ejército regular. Salvo contadas unidades estas fuerzas se pasaron al ejército de Aguinaldo con armas y bagajes sin que los escasos jefes europeos que las mandaban pudiesen evitarlo, dándose por contentos estos con poder salvar la vida en el mejor de los casos.

Los combates del día 1, batalla naval de Cavite, y 2 de mayo, rendición del arsenal y de la plaza de Cavite, permitieron a Dewey demandar a Augustín la rendición inmediata de la plaza de Manila, a lo que éste se negó, comprendiendo que la rendición de la capital de la colonia suponía el final de la presencia española en Filipinas.

El mando norteamericano, a pesar de la negativa, no procedió - como esperaban las autoridades y población de Manila - al bombardeo y subsiguiente asalto: la escuadra yanki había gastado la mayor parte de su munición, siéndole muy difícil reponer sus pañoles al estar a unas 7.000 millas de su base más cercana. Además los efectivos terrestres con que contaban eran relativamente escasos, y, a pe-

5 Vid. Saturnino Martin Cerezo, La pérdida de Filipinas, Madrid, H16,1992.

6 En breve publicaré un estudio del manuscrito prácticamente desconocido relativo a la actuación de la fuerza mandada por el teniente coronel ALBERTí LEONES titulado 500 hombres del $12^{\circ}$ de cazadores en el sitio de Sta. Cruz de La Laguna. Sobre esta cuestión poco conocida ver también Antonio DEL Río, Sitio y rendición de Santa Cruz de La Laguna, suerte de la Colonia, Manila, Imprenta del Diario de Manila, 1899.

R. I., $1998, \mathrm{n}^{\circ} 213$ 
sar de contar con el apoyo de la fuerzas de Aguinaldo, no podían arriesgarse a una derrota terrestre de consecuencias impredecibles ante los españoles y ni siquiera a una victoria pírrica que pusiese el archipiélago en manos de los tagalos.

La toma de Cavite permitió la llegada de Aguinaldo a Luzón, desde donde procedió a levantar a la población tagala, armándola gracias al dinero entregado por España en Biac na Bató y a las armas y municiones regaladas por los norteamericanos. Desde este momento los combates se extendieron por todo Luzón, siendo el cerco sobre la ciudad una realidad, día a día más fuerte. La dureza de los combates en torno a la ciudad - como en todo el archipiélago- fue muy grande, hecho que viene avalado por sucesos como los acaecidos con la columna del general Peña, que había salido de Cavite, con unos efectivos de unos 1.500 hombres, de ellos 650 peninsulares, no pudo llegar a Manila de la que sólo le separaban escasos 30 kilómetros ${ }^{7}$. Las columnas enviadas desde Manila para apoyar los intentos de avance de Peña no lograron su objetivo, a pesar de contar cada una de ellas con 500 hombres $^{8}$.

El 1 de junio la ciudad fue definitivamente sitiada por tierra, siendo el asedio ya total, dado que desde principios de mayo la flota de Dewey había logrado el bloqueo naval de la bahía de Manila. Por tierra y mar la ciudad estaba dejada a su propia suerte, siendo la llegada de refuerzos por tierra casi imposibles y por mar la única esperanza centrada en la lejana escuadra de Cámara.

Los combates, asedio y asalto, se habían de prolongar a lo largo de 105 días, entre el 1 de mayo y el 13 y 14 de agosto de 1898. Los

7 Juan y José ToRal, 1898. El sitio de Manila, memorias de un voluntario, Madrid, Editora Nacional, 1942, p. 56.

8 Para un combate colonial, contra nativos, las fuerzas que actuaban en esta operación eran muy numerosas. Hay también que considerar que estamos hablando de los primeros días de la guerra, cuando aún la fuerzas de Aguinaldo no estaban perfectamente organizadas y armadas. Estos datos son muy importantes para evaluar la cantidad y capacidad de resistencia y ataque de los tagalos de Cavite. No olvidemos que tanto españoles como indígenas eran en muy alto porcentaje los mismos veteranos que habían hecho la recién terminada guerra de 1896/97. Durante la guerra de Indochina, una fuerza formada por dos regimientos de legionarios franceses, fracasó en una situación parecida, al intentar retirarse de Cao Bang hacia That Khé por la carretera R.C.4. Tanto en un caso como en otro la resistencia debió ser durísima ya que ambas columnas, lastradas eso sí con muchos civiles, fracasaron en su empeño. A pesar de todo las unidades europeas, cuando combatían con enemigos indígenas, y a pesar de estar en minoría, solían salir victoriosas sin muchos problemas. 
combates con las fuerzas tagalas que asediaban la plaza fueron constantes e ininterrumpidos y de una intensidad notable.

Durante el mes de mayo se había reorganizado la defensa de la ciudad en dos líneas, la llamada defensa exterior, y un débil y sin completar sistema de trincheras conocido por defensa interior apoyado en la viejas defensas de la ciudad amurallada ${ }^{9}$.

Para la defensa de la plaza se disponía de las siguientes fuerzas: $\mathrm{La}$ defensa exterior estaba basada en algunas construcciones ya existentes y en los blocaos, mandados construir por Primo de Rivera, y un sistema de trincheras de nueva construcción. La guarnición de Manila, se dividió en sectores: El derecho mandado por el general de artillería Arizmendi y los tenientes coroneles del mismo arma Golobardas y Bonet con unos efectivos de 1.500 hombres; El centro, mandado por el general de ingenieros Rizzo, el coronel Rosales y los tenientes coroneles Calderón y Manzanares, con 900 hombres; El izquierdo lo mandaba el general Palacios primero y el coronel Carbó después, contando 500 hombres entre carabineros, voluntarios pampangos, marinería y fuerzas de artillería de plaza. A este dispositivo se unían cinco sectores o líneas mandados respectivamente por: Línea Muntilupa a La Piñas, por el coronel Victoria Pintos, con 930 hombres de los que sólo 230 eran fuerzas regulares, siendo el resto parte del tercio Anda Salazar, que luego se pasarían en masa a los tagalos. La línea Muntinlupa a Taguig, responsabilidad del coronel Lasala y el teniente coronel Rosetti, disponía de 500 hombres de los cuales sólo 100 pertenecían al ejército peninsular. La línea Tambobong, Montalbán y Mariquina la mandaba el coronel Carbó, tenían 450 efectivos, la mayoría indígenas. Existían dos líneas menores a cargo del coronel Alberdí - entre Santa Misa y San Juan del Monte - y el teniente coronel Colorado - San Juan del Monte- que contaban con fuerzas del batallón de ingenieros, tropas nativas y unos 200 peninsulares. Como refuerzo se crearon tres columnas volantes, con 1.600 hombres en total, bajo el mando de los tenientes coroneles Soro, Hernández e Iglesias, a los que luego se sumó la mandada por Dujiols. Para vigilar los arrabales de Manila se creó una columna mandada por el coronel Pintos, con 400 soldados peninsulares, los voluntarios europeos de las guerrillas de San Miguel y del Casino,

\footnotetext{
9 Este último se mostraría, como veremos, totalmente incapaz de resistir los ataques en los últimos momentos del asalto.
}

R. I., 1998, n. $^{\circ} 213$ 
cinco compañías de voluntarios y tres de los llamados provisional. Tenían como misión vigilar puentes, edificios y algunas calles fundamentales de la plaza. En total las fuerzas españolas que guarnecían la ciudad eran de unos 6.500 a 7.000 hombres, buena parte de ellos nativos, con la misión de proteger un perímetro de unos 15 kilómetros, en el que se encontraban refugiadas unas 70.000 personas $^{10}$.

Es relativamente poca la información con que contamos sobre la batalla de Manila, las narraciones más detalladas son las aportadas por algunas memorias de aquellos que participaron en los combates y vivieron desde la ciudad estos días. Esta documentación es interesantísima, pero incompleta, a la que se hace necesario unir para comprender en toda su magnitud estos sucesos los diarios de operaciones de las diversas unidades que participaron en la defensa junto a otros documentos de índole militar y civil que aún se encuentran sin estudiar dentro de nuestros archivos. Está documentación, hasta ahora casi desconocida, es de difícil localización, dada la mala catalogación de los Archivos de las Fuerzas Armadas, unido a la circunstancia que muchas de las fuerzas que allí combatieron fueron batallones de cazadores - unidades formadas aprisa y corriendo para ser enviadas a Filipinas y por tanto carentes de toda infraestructura e historia- o de voluntarios, problema al que se une el hecho de la atribulada salida de la colonia como consecuencia de su repatriación fruto de la derrota, con la subsiguiente pérdida de documentación, lo que hace que el conocimiento de estos sucesos sea escaso o, en el mejor de los casos, sesgado fruto de sólo tener acceso a algunas fuentes parciales, lo que sin lugar a dudas no permite una visión tan completa como sería deseable de estos acontecimientos ${ }^{11}$.

A lo largo de los meses de mayo, junio, julio y agosto, las numerosísimas fuerzas de Aguinaldo,cada día mejor armadas, intentaron sin éxito romper la línea exterior de defensa de la ciudad. Los ataques de los tagalos, a pesar de estar muy mal organizados, resultaban peligrosos dada la extensión del perímetro de defensa, y aunque estas fuerzas no tenían un armamento muy moderno - tenían poca artillería y la

10 J. y L. TORAL [7], pp. 195 a 199.

11 Esperamos que en breve la documentación española de la época colonial, que se encuentra en el archivo de Manila, podrá ser consultada en Madrid gracias a un proyecto de investigación y de filmación sistemática de todo este archivo iniciado y dirigido por el Dr. Francisco de Solano, en el que trabajó Belén Bañas, y que sigue realizando en la actualidad un equipo del CSIC. 
que tenían la empleaban muy mal - su gran número - 30.000 con armas de fuego y unos 100.000 con armas blancas-convertían sus ataques en verdaderamente peligrosos. Cualquier fallo en la potencia de fuego de los defensores, que permitiese al enemigo acercarse en fuerza a la línea defensiva, hubiese supuesto la ruptura del frente y el fin de la resistencia.

Mientras que las fuerzas tagalas acosaban noche y día las líneas españolas, los norteamericanos esperaban pacientemente concentrando más y más fuerzas de infantería en espera de dar el asalto definitivo: a mediados de junio la brigada de Thomas M. Anderson desembarcó en Maytubing, acampando por los alrededores de Cavite y en las playas de Parañaque.

A medida que transcurrían las semanas la situación empeoraba por días; las trincheras de los tagalos se acercaban más y más a la línea exterior de defensa de la plaza y las deserciones de las tropas nativas aumentaban en directa proporción con el endurecimiento de los combates. El coronel Lasala se había tenido que replegar al interior del ya citado sistema de blocaos, salvo en los sectores de Santa Ana, San Juan del Monte y Santolán. El bloqueo ya era un realidad frente al cual los defensores nada podían hacer salvo resistir.

Las carencias entre la población civil y las tropas eran cada día más acuciantes, hecho que se agravó como consecuencia de haber tenido que retirarse la fuerza que defendía la posición llamada Santolán, en la que estaba la bomba que nutría de agua la ciudad, lo que obligó a su racionamiento -3 horas al día-, pudiéndose resistir gracias a que las lluvias del monzón llenaron los viejos aljibes de la ciudad.

Los días 22, 26 y 27, y 30 de julio se produjeron fuertes ataques por parte de numerosos grupos nativos que finalmente pudieron ser rechazados. Aguinaldo quería tomar la ciudad sólo, con sus propias fuerzas, antes de que el asalto inevitable de las tropas yanquis se produjese. El control de Manila por sus partidarios le habría supuesto un paso transcendental para el logro de la independencia.

El 31 de julio las fuerzas norteamericanas estaban ya lista para el asalto de la ciudad. La flota de Cámara había recibido la orden de regresar a la Península. La suerte estaba echada, todo terminaría el 13 de agosto.

R. I., $1998, \mathrm{n}^{\circ} 213$ 
EL "DIARIO DE LOS SUCESOS OCURRIDOS DURANTE LA GUERRA DE ESPAÑA CON LOS ESTADOS UNIDOS, 1898” ESCRITO POR UN MIEMBRO DE Misión DE LA COMPAÑía DE JESÚS EN LAS ISLAS FILIPINAS, DEPOSITADO EN EL ARCHIVO DE LA COMPAÑÍA EN ROMA.

El manuscrito que nos ocupa narra de forma breve y concisa, día a día, las vicisitudes de los habitantes de Manila, su percepción de los cercanos combates en la línea defensiva, por la pluma de un jesuita residente en la ciudad. Visión privilegiada por ser la Compañía de Jesús, sus miembros, grupo poderoso en la sociedad manila. Es anónimo, y de él sólo vamos a extraer - ya que es muy extenso y prolijo- aquellas referencias y noticias relativas al asedio de Manila durante aquellos luctuosos sucesos de hace un siglo. El diario abarca desde el día viernes 21 de abril de 1898 hasta el martes 7 de febrero de $1899^{12}$.

Viernes 22.

"Se recibe en Manila la noticia de la ruptura de relaciones diplomáticas entre España y Estados Unidos".

La guerra fue declarada por los Estados Unidos con fecha 25 de abril, con carácter retroactivo al 21 para dotar de legalidad el bombardeo por la Marina estadounidense de Matanzas, así como el apresamiento de varios buques españoles que estaban en aguas de los Estados Unidos. Woodford, encargado de dar el ultimatum a España previo a la declaración de guerra, se encontró que en el momento que iba a cursar éste, el día 21 , recibió noticias de que los combates ya habían comenzado

Domingo 24.

"Recorre la ciudad dirigiéndose a Malacañang una patriótica manifestación de todas las clases del pueblo por España contra los Estados Unidos".

La noticias de una casi inevitable guerra con los Estados Unidos hizo que las calles de Manila fueran presa de una oleada popular de fervor patriótico y españolista. Algunos de los recién indultados líderes del katipunan - Trías, Pío del Pilar, Mójica, Riego de Dios, Ricarte,

12 En cursiva va el texto del diario. 
etc.- - se dirigieron a Capitanía para ponerse al servicio de las autoridades. Una manifestación de adhesión a la causa de España recorrió las calles de la ciudad entre los aplausos y vítores de la población.

Martes 26.

"Sábese en Manila que la escuadra americana se retiró de HongKong á Mirs-Bay los días 24 y 25 del actual"

La escuadra del Pacífico del comodoro Dewey desde mucho antes del estallido del «Maine» se estaba preparando para realizar un ataque sobre las Filipinas. El Naval War College, desde 1895, tenía ya preparados planes bélicos contra España en los cuales se contemplaba un ataque a las posesiones españolas en Asia, para ya en junio de 1896, concretarse este plan el teniente William W. Kimball, "que aunque seguía considerándolo como secundario, creía que el Escuadrón Asiático podía reducir y conservar Manila, controlando así el comercio de las Filipinas y tanto en el caso que se decidiera conservarla a título de indemnización como en de ser utilizada como moneda de cambio en la negociación posterior de paz"13.

Esta flota desde semanas antes se estaba preparando para la guerra. El 25 de febrero el subsecretario de Marina Theodor Roosevelt, había enviado un telegrama a Dewey ordenándole dirigirse a Hong Kong ante una eventual guerra contra España. En este puerto se procedió al amunicionamiento al completo de sus pañoles, el pintado en gris - color de tiempos de guerra- de los buques que hasta entonces tenían color blanco, etc. Todo con el beneplácito y la aquiescencia de las autoridades británicas de esta colonia ${ }^{14}$. Al estallar las hostilidades, la escuadra de Dewey se vio obligada a abandonar el puerto de Hong Kong, anclando en la muy cercana y segura bahía de Mirs, formalidad que no impidió que desde allí siguiesen contando con el apoyo mal disimulado de los británicos.

Miércoles 27 de abril.

“(...) La escuadra norte-americana sale de Mirs-Bay con rumbo a Manila".

13 Agustín R. Rodriguez, La caída de Manila en 1898: Estudios en torno a un informe consular, en Monografias de A.E.E.P., Madrid, A.E.E.P., (en prensa).

14 Antonio Molina, Historia de Filipinas, Madrid, ICI, 1984, p. 396.

R. I., $1998, \mathrm{n}^{\circ} 213$ 
Domingo 1 de Mayo.

"Hoy nuestra escuadra ha sido incendiada por la escuadra americana (...) La componen los barcos "Boston" y "Baltimore" cruceros protegidos de $1^{a}$ clase. "Ralleig" y "Olimpia" cruceros protegidos de $2^{a}$ clase; cañoneros protegidos "Concord" y "Petrel", aviso "Mac-Culloch" y transporte "Zafiro" y "Naushau" (...) si el Corazón Divino se dignase conceder la victoria á las armas españolas. Dicha oración es como sigue (...) Los barcos que se han librado del fuego han sido hechados á fondo por sus tripulantes que no han podido sufrir que cayeran en poder del enemigo (...) Son como unas 450 las bajas que han sufrido hoy nuestra marina”.

La derrota de la escuadra española en Cavite resultó determinante para la suerte de la presencia española en Asia. El hundimiento de la ya maltrecha escuadra por parte de los propios marinos españoles supuso la entrega de la colonia a los yanquis. Una victoria que no tuviese el carácter de absoluta, total, sólo implicaba que más tarde o más temprano las fuerzas de Dewey se tendrían que retirar a su lejanas bases, siendo estas operaciones únicamente una distracción en la campaña principal del Caribe, un desgaste a los siempre menguados recursos de España ${ }^{15}$. Esto no lo comprendió Montojo. Sus erróneas decisiones durante y después de la batalla dieron la victoria absoluta a Dewey.

Lunes 2.

"Una batería de 4 cañones recién montada en la escollera del puerto en construcción, ha sido desmontada durante la noche y traída á Manila, pues por su posición estaba muy expuesta á que la volasen los enemigos con una lluvia de granadas. (...) No ha habido bombardeo (de Manila). (...) A medio día después de telegramas cruzados entre el Gobernador militar de Cavite y el Capitán Gral.de Manila ha sido abandonada la plaza de Cavite por nuestras tropas. Muchos indios han recogido armas del Arsenal y las han presentado

15 Para estudiar con más detalle la batalla naval de Cavite ver, ANóNIMO, La batalla de Cavite (1898), Madrid, Amigos de la Historia, 1972. Así como los diversos trabajos de Agustín R. RodRíGUEZ, entre los que destacan La caída de Manila en 1898: Estudios en torno a un informe consular; La Guerra del 98. Las campañas de Cuba, Puerto Rico y Filipinas; El desastre naval del 98. Igualmente mi trabajo 1898, la guerra HispanoNorteamericana en Filipinas en El Ejército y la Armada en 1898. 
a la autoridades españolas de Cavite que han establecido su gobierno en S. Francisco de Malabón. Los americanos han tomado posesión de la plaza y Arsenal de Cavite".

Con la toma de esta base, tan necesaria para ellos, los americanos se dispusieron a reavivar la rebelión tagala facilitando la llegada del líder Aguinaldo al archipiélago, al tiempo que entregando grandes cantidades de armas a sus partidarios. Frente a éstos las autoridades de Manila comprendían que la única posibilidad de conservar la soberanía de España en el archipiélago estaba ineludiblemente unida a lograr que la población nativa permaneciese fiel y dispuesta a verter su sangre en favor de la Corona. Sastron, testigo de todos estos sucesos hace la siguiente reflexión: "Con el país filipino a nuestro lado nada temíamos: el conocimiento exacto de nuestros escasos medios para una guerra interior; el verdadero inconcebible abandono en que vivíamos para sostener una del exterior, ninguna de estas dos circunstancias mermaban en lo más mínimo la legítima esperanza que hubiéramos podido abrigar de obtener éxito en la contienda, siempre y cuando los naturales filipinos nos fuesen fieles"16.

"Han sido propuestos y aprobados como medios de atracción: $1^{\circ}$ el crear milicias de voluntarios indígenas cuyos individuos puedan ascender hasta el empleo de Coronel sin que estos cargos sean incompatibles con otros cargos civiles que puedan ejercer en sus respectivos pueblos. $2^{\circ}$ Crear una Asamblea consultiva de Filipinas, sin poderes administrativos, en la que puedan ser admitidos entre otros, algunos individuos de patriotismo sospechoso que convenga atraer si darles armas de que puedan abusar. $3^{\circ}$ La creación para los indígenas de títulos nobiliarios a que se hagan acreedores por actos de patriotismo y el abrirles el paso a los empleos públicos de confianza, incluido el de Gobernadores de provincia, cuando hubiese quien por su talento y probidad lo mereciese".

Dado el cariz que tomaban los acontecimientos, el general Augustín, por un decreto de 4 de mayo de 1898, creó una Asamblea Consultiva con el objetivo de sumar a indígenas y peninsulares al

\footnotetext{
16 Manuel SASTRON, La Insurrección en Filipinas y la guerra hispano-norteamericana en el archipiélago, Madrid, 1901, p. 368.

R. I., 1998, n. $^{\circ} 213$
} 
esfuerzo de guerra contra los Estados Unidos. Se reunió por primera vez el 28 de mayo en el salón de sesiones del Ayuntamiento. En ella el Capitán General manifestó el deseo del gobierno de cumplir las aspiraciones reformistas de los filipinos a cambio de su participación en la guerra. El discurso fue contestado por Pedro A. Paterno -el artífice de los acuerdos de Biac na Bató- que demandó una amplia autonomía, cercana a la independencia, a cambio de la fidelidad de los filipinos a la bandera de España. Pocos días después Paterno, el 31, dio a la opinión pública un manifiesto: "Mas por grandes esfuerzos que hagamos nosotros mismos, necesitaremos de una aliada. Imitemos el ejemplo de las grandes potencias del mundo; no se bastan a sí mismas: por fuertes y grandes que sean, buscan auxilios y ayuda, sumandos de fuerza, aumentos de poder. Rusia busca a la Francia, Alemania a Italia y la Austria. ¡Infeliz de la que se aísla! ¿Y qué mejor aliado para nosotros que España, nación con quien nos unen cerca de cuatrocientos años vínculos de relaciones, de religión, de derecho, de moral, de usos y costumbres, conociendo a diario sus virtudes y defectos?"17.

Dicho manifiesto despertó la indignación entre la población europea de Manila, pero la necesidad de contar con el decidido apoyo de los tagalos, con la fidelidad de la milicia filipina, hizo que estas palabras fuesen aceptadas. Pero estas medidas no pudieron frenar la agitación en que vivía la población indígena. A finales de mayo aún parte de las milicias filipinas eran fieles a España. Poco tiempo faltaba para que sus jefes, los Trías, Tirona, Ricarte, Pío del Pilar, Diego de Dios, etc., desertasen masivamente al lado de Aguinaldo.

\section{Martes 3.}

"La escuadra americana dueña de la bahía se entretiene en incendiar barcos mercantes".

Dewey exige la rendición de Manila con la amenaza de arrasar la ciudad, para luego exigir, según el autor del manuscrito:

" 1 a Entrega de todos los barcos de guerra que quedan en el Archipiélago: $2^{a}$ Entrega de todos los marinos como prisioneros de guerra: $3^{a}$ Reconocimiento oficial del bloqueo en que están las islas".

\footnotetext{
17 Ibidem, p. 436.
} 
Estas medidas parecieron no dar resultado en los primeros momentos. La inoperatividad de la escuadra yanqui hizo recobrar a las autoridades y defensores de Manila parte de su confianza. Es cierto que la insurrección entre la población de Luzón se extendía como la pólvora, siendo los combates con éstos los únicos que se producían en la colonia, tomando un cariz y virulencia insospechados, pero el hecho de haberse librado la ciudad del bombardeo había levantado la moral de toda la población.

Jueves 12.

"El cañonero español Callao que venía de la Paragua ha entrado en bahía y se ha metido candorosamente entre los barcos norteamericanos que lo han apresado".

Ese mismo día logró el vapor «Esmeralda» romper el bloqueo y así se pudo enviar correspondencia y cablegramas a la Península”.

Miércoles 18.

"Entra en la bahía un vapor de guerra Japonés. Háblase de una gran batalla naval, habida en aguas de Cuba entre nuestra escuadra y la Americana, y se dice que los Jesuitas hemos recibido el telegrama que da cuenta de ella, y aun se pasan copias de él por Manila. Es todo falso".

En estos días - como a lo largo de todo el asedio- numerosos buques de guerra de diversas potencias se dirigieron a Manila ante los acontecimientos que en ella se estaban produciendo. Navíos de guerra con bandera británica, alemana, francesa y japonesa anclaron ante la ciudad. Alemanes, y en parte japoneses, estaban abiertamente en favor de España, sin recatarse en lo más mínimo, los primeros, en demostrar su decidida toma de posición. Todos las memorias e informes de los españoles que vivieron estos sucesos indican en algún momento su convicción de que la escuadra alemana terminaría por interponerse entre ambos contendientes impidiendo la caída de la plaza.

Viernes 20.

"Corre por Manila la estupenda noticia de que los Jesuitas han recibido un telegrama que da cuenta de una gran victoria naval en aguas de Cuba. Pasan de mano en mano por la población copias de tan bello documento y con esta ocasión recibimos visitas de perso-

R. I., 1998, n. $^{\circ} 213$ 
nas de importancia que vienen a enterarse de lo que hay sobre el particular. Desgraciadamente la victoria y el telegrama son invención de gente despreocupada. Los yanquis rompen el cable telegráfico de Manila a Visayas".

Sábado 21.

"Por el resultado que pudieran tener los manejos de Aguinaldo y sus compañeros se trabaja con gran actividad en el atrincheramiento de la ciudad y alrededores".

Martes 24.

"Con esta fecha publica Aguinaldo desde Cavite una proclama y dos decretos dictatoriales".

Aguinaldo llegó a las Filipinas sobre el día 17 de mayo, dando acto seguido el siguiente manifiesto: "Vuelvo a asumir el mando de todas las huestes para el logro de nuestras levantadas aspiraciones, estableciendo un régimen dictatorial que se traducirá en decretos bajo mi sola responsabilidad, y mediante consejo de personas ilustradas, hasta que, dominadas completamente estas islas, puedan formar una Asamblea constituyente republicana y nombrar un presidente con su Gabinete, en cuyas manos resignaré el mando de las mismas. Dado en Cavite el 24 de mayo de 1898"18.

A partir de su arribada a Cavite comenzó una ingente labor encaminada a levantar al país y a organizar algún tipo de gobierno. Los reclutas fluían a sus filas, incluidos muchos de los voluntarios de la milicia filipina que se pasaban con armas y bagajes. El 12 de junio de 1898 Aguinaldo proclamaba unilateralmente la independencia de la república filipina: "Se señala el día 12 de este mes para la proclamación de la independencia de este nuestro querido país en el pueblo de Cavite viejo, a cuyo acto, para su debida solemnidad, deben concurrir los jefes de los puestos de nuestras fuerzas o sus representantes, a quienes se trasladará este decreto, pudiendo asistir cuantos quieran los notables que figuran en nuestra comunión política, como el señor almirante de la escuadra norteamericana, los señ̆ores co-

18 Ibidem, p. 421. 
mandantes y oficiales a sus órdenes, a quienes se pasará atenta comunicación de invitación, y suscribiendo todos el acta que se levantará por el funcionario que tengo a bien comisionar. Dado en Cavite a 9 de junio de 1898. El dictador Emilio Aguinaldo ${ }^{19}$.

El 15 de julio Aguinaldo disuelve el Katipunan por causa de los deseos de ciertos sectores de éste encaminados a que sean sólo sus miembros los que ocupen el poder en la nueva nación que se quiere crear $^{20}$. Aguinaldo, que ya había fusilado al fundador del Katipunan, Bonifacio, y ocupado su puesto como líder de los katipuneros, decide su desaparición consolidándose como único jefe de las fuerzas filipinas.

El 23 de julio da decreto por el que se autonombraba jefe de un gobierno que pasaba a llamarse Gobierno Revolucionario, dedicando frases de elogio a los Estados Unidos por su apoyo a la causa de la independencia de Filipinas. La sede de este gobierno fue trasladada desde Cavite, primero a Bacoor y luego a Malolos. El 6 de agosto este gobierno, ante los presidentes municipales de dieciséis provincias de Luzón, reunido en asamblea en el pueblo de Bacoor, ratifica la independencia. Aguinaldo no contaba con los designios que ya tenían trazados los Estados Unidos

Miércoles 25.

"El Teniente Coronel de Artillería Sr. Bonet Jefe de las baterías de las murallas ha pedido permiso a R. P. Rector para dirigir desde la torre del Observatorio del Ateneo, la defensa de la plaza, a cuyo fin se instala en dicha torre un telefono y un tapanco".

Viernes 27.

"Trabajase con grande actividad en el atrincheramiento de la ciudad y alrededores, en previsión de algún desembarco de yanquis o de un ataque de los insurrectos".

Sábado 28.

"Dicese que en río de Imus han hecho los yanquis un amago de desembarco protegido por el cañonero "Callao" pero han sido valientemente rechazados por los voluntarios de Imus que les han he-

\footnotetext{
19 Ibidem, p. 459.

20 A. Molina [14], pp. 423 y ss.
}

R. I., $1998, \mathrm{n}^{\circ} 213$ 
cho 17 bajas. Este es el rumor que corre, pero no se puede responder de la exactitud de la noticia. (...) En la casa del Ayuntamiento de Manila se ha reunido por primera vez la Asamblea consultiva".

Domingo 29.

“(...) Por los diarios de Hong Kong se sabe: $1^{\circ}$ que á últimos de este mes ha debido salir de Cádiz una Escuadra Española que se cree viene á Filipinas, compuesta de un acorazado, siete cruceros y tres torpederos; $2^{\circ}$ que nuestra escuadra de Cuba ha obligado a los Yanquis por lo menos de momento a levantar el bloqueo de todas las costas, $3^{\circ}$ que Aguinaldo ha recibido del Comodoro Dewey 500 rifles con 200.000 cartuchos. Corren rumores de que en Cavite dos compañías de indígenas del Regimiento $n^{\circ} 74$ se han pasado al enemigo y que casi han exterminado a una Compañía de Infantería de marina que andaba con ellos. En Bulacán hay mucho peligro de insurrección. Hay alli muchos hombres armados con fusiles procedentes de la escuadra enemiga. Aguinaldo ha enviado emisarios á muchas provincias á preparar el levantamiento del país".

Lunes 30.

"Entre cinco y seis de la mañana óyese tiros de fusilería al parecer en Bacoor. En un reconocimiento que han hecho nuestras tropas por la parte de Bacoor han tenido un encuentro con el enemigo compuesto de yanquis e insurrectos. El combate ha durado hasta las tres de la tarde hora en que se han retirado nuestras tropas á desayunar. Nuestras bajas han sido 6 muertos y varios heridos. Las del enemigo han sido muchas. Hay noticias de haberse levantado muchos insurrectos en La Laguna los cuales han impedido un desembarco de nuestras tropas en Calamba".

Martes 31 de Mayo.

"Salen de Manila para el Zapote tropas de Artillería y cazadores. Salen del río los vapores Españoles "Salvadora" y "Elcano" con bandera alemana, y el "P. de Sotolongo" con bandera Francesa alquilados por las respectivas colonias de aquí para acogerse allí junto a sus barcos de guerra. Sopla un fuerte baguio con mucho agua que ha impedido las operaciones militares en Cavite. -Dicese que en Bulacán ha habido también levantamientos promovidos por Agui- 
naldo en combinación con lo de Cavite. Reina mucha inquietud. Han roto la línea del tren de Manila á Dagúpan y los telégrafos de Cavite y Bulacán".

Mientras que los cónsules y colonia europea residente en Manila, por lo general, se declaraban abiertamente partidarios de la causa de España, los británicos - y muy especialmente su cónsul, que ahora representaba también los intereses de los Estados Unidos- lo hacían a favor de los atacantes, llegando incluso a facilitar información y suministros - portados por buques británicos - a los hombres de Dewey.

"Durante todo este tiempo hay mucho disgusto en la gente contra la mayor parte de la Colonia Inglesa de aquí, y sobre todo contra el Consul Inglés. Acusales la voz pública de adictos á los yanquis y el mismo Cónsul parece que no se recata de profetizar á todas horas un pronto desenlace de los actuales sucesos en favor de los yanquis. Como Cónsul interino que es de los Estados Unidos va todos los días a visitar á Dewey y jamás, preguntado por los Españoles, sabe una palabra de lo que ocurre en la escuadra enemiga".

Miércoles 1 de Junio.

"Han cesado el viento y la lluvia pero queda el cielo nublado. Desde el mediodía hasta la noche se oye grande estruendo de cañonazos y descargas cerradas en el Zapote. Son de nuestras tropas que refuerzan la línea mientras se está librando otro combate en el interior de la provincia (...). Nuestra artillería compuesta de 372 soldados no ha tenido en toda la tarde una sola baja, gracias a Dios. La de los insurrectos y tropas del interior son desconocidos".

\section{Jueves 2 .}

"Durante la noche se han oído cañonazos en Cavite, y esta mañana fuego de fusilería y cañones. Por fin el Gral. de Cavite Sr. García Peña se ha entregado al enemigo con 900 soldados de infantería y 80 artilleros con armas y municiones. Cunde la insurrección mas y mas en las provincias tagalas, con lo que la gente que había salido fuera de Manila por temor al bombardeo, vuelve ya á ella huyendo de los insurrectos".

\footnotetext{
R. I., $1998, \mathrm{n}^{\circ} 213$
} 
La Junta de Defensa de Cavite decidió, como ya hemos señalado, que la guarnición evacuase la ciudad. Se informó al Capitán General y se procedió al abandono de la ciudad, llevando la caja y cuatro piezas de $80 \mathrm{~mm}$, transportadas a brazo por los artilleros. Con la guarnición salió la población europea y buena parte de la nativa. No quedaron en Cavite más de una docena de familias. Inmediatamente 500 o 600 tagalos entraron en la ciudad y se dedicaron al saqueo de la misma ${ }^{21}$.

Peñas se retiró hacia los pueblos más cercanos de la provincia, Noveleta, Cavite Viejo y Bacoor, Nair y Rosario, Binacayan y Parañaque, San Francisco de Malabón e Imus. Desde un primer momento su situación fue muy comprometida, dado que la provincia de Cavite era donde los seguidores de Aguinaldo tenían más partidarios. Conociendo en Manila esta situación se envió a la columna del teniente coronel Soro, con quinientos hombres, para socorrer al general Peña y a sus hombres, pero ésta no pudo alcanzar su propósito por causa de la gran resistencia que encontró en su avance, a pesar de la corta distancia que les separaba.

La plaza y provincia de Cavite se convirtió, igual que en el pasado, en el corazón de la actividad insurrecta. El armamento dado por los americanos y compradas por Aguinaldo comenzaron a entrar por este puerto para armar a las, cada día más fuertes y numerosas, tropas de Tagalas. La situación tomó desde el principio tal gravedad que algunos de los jefes tagalos de las milicias fieles a España decidieron no repartir las armas entre sus hombres por miedo al uso que estos hicieran de ellas.

La resistencia que intentó librar las fuerzas de Peña, básicamente de la Guardia Civil, Infantería de Marina y voluntarios, fue finalmente vencida. A finales del mes de mayo estas fuerzas estaban prácticamente prisioneras o sitiadas y carentes de toda esperanza en las posiciones que ocupaban en Bacoor, Imus, Dasmariñas, Silang, etc. El día 30 de mayo, fecha señalada por Aguinaldo para el levantamiento general del país, comenzó el ataque y asedio de las posiciones que los aproximadamente 2.800 hombres de la guarnición en la provincia de Cavite aún mantenían. Su resistencia se prolongó en

\footnotetext{
21 Esta estaba compuesta por dos compañías del regimiento de línea $\mathrm{n}^{\circ} 74$, una de infantería de marina y una sección de artillería de 50 hombres. En total unos 1.500 hombres, de los cuales sólo 650 eran penínsulares.
} 
algunos lugares varias semana, mientras que tuvieron munición y alimentos. Tras duros combates el general Peña y todos sus soldados fueron apresados por los tagalos.

Viernes 3.

"Esta mañana ha habido tiroteo en Cavite hasta las 10 de la mañana. Dicese que tenemos fuerzas sitiadas por los insurrectos en $\mathrm{Ca}$ vite-viejo".

Sábado 4.

"Sábese que ha salido de la Península una escuadra española el 28 de Mayo la cual todos creen que viene acá si bien á muchos les parece mal que haya salido de España tan tarde. Reúnese de nuevo la asamblea consultiva para la aprobación del reglamento. Corren noticias alarmantes pero confusas de la Laguna y Bulacán. Dicese que la línea férrea de Manila á Dagúpan está interrumpida en una extensión de 14 kilometros. El Comandante de Sta. Ana Pío del Pilar se ha dejado copar fraudulentamente por el enemigo cerca de Parañaque con 5 compañias. Algunos de los suyos al ver la estratagema se han venido huyendo a nuestro campo".

\section{Domingo 5.}

"Esta noche ha sido de mucho tiroteo: los insurrectos han pasado el Zapote por un punto no defendido por nuestras tropas. Otros insurrectos han hecho un desembarco mas allá de Malate. Reina grande alarma y hay mucho movimiento de tropas y cañones. No se ve en la torre de Imus una bandera blanca y roja que ha ondeado por espacio de ocho días, y en tiempo de guerra significa "sin novedad". En las Piñas ondea una bandera blanca y negra que dicen sea la de la insurrección. Así se divisa desde el Ateneo con el anteojo.

Se ha dado órdenes de venir á Manila á las tropas que guarnecían algunas líneas de defensa algo apartadas de la Capital, quedando constituidas las avanzadas de la defensa de la plaza por una línea semicircular de trincheras distantes cuatro ó cinco kilómetros de la ciudad murada, cortadas por 15 blokaus ó sean casas de madera y tierra atrincheradas. Esta línea de trincheras comienza en la playa de Caloocan y termina en la del polvorín de S. Antonio Abad. (...) Hay bastante descontento entre los Jefes y oficiales del ejército

R. I., 1998, n. $^{\circ} 213$ 
de parte de los voluntarios y de los no voluntarios (ya que á todos los españoles seglares se ha obligado á tomar las armas)".

En relación a estos sucesos el cónsul portugués los narra en los siguientes términos: "Los cabecillas brotaban en las provincias de la isla de Luzón, y poco a poco se iban apoderando de los pequeños destacamentos. Los insurrectos pasaban el río Zapote, línea natural de defensa de Manila. Pío del Pilar, Felipe Buencamino, Trías, Ricarte y otros muchos abandonaban las filas leales para ayudar al enemigo (...) El cerco de Manila se iba estrechando diariamente hasta quedar reducido a la línea de blockhaus, y estos pequeños fuertes no fueron abandonados también por la resistencia que a cumplir la orden puso el cuerpo de Artillería, y desde entonces, o sea, desde el $1^{\circ}$ de Junio, el soldado español se bate denodadamente contra fuerzas insurrectas muy superiores en número, ya bajo un sol tropical que funde los huesos de cráneo, ya bajo lluvias torrenciales que los entierran en el fango; pero sin decaer un momento en sus entusiasmos y sin perder la animación y la alegría (...) Esta heroica defensa de los blockhaus y trincheras ha permitido a las autoridades militares poner a la ciudad murada en mejores condiciones de defensa"22.

El primer gran ataque se produjo el 5 de junio. Una columna de entre 4.000 y 5.000 tagalos atacó las posiciones defendidas por el tercio de Bayambang, compuesto por tropas indígenas fieles a España, mandados por el capitán Acevedo y formado por 300 hombres. Tuvieron que retroceder a Taguig donde estaba el jefe del sector izquierdo, coronel Lasala con otros 300 hombres más, viéndose obligados a replegarse todos hacia Guadalupe, gracias al apoyo de las fuerzas del capitán de fragata Juan de la Concha, compuesta por marinería y tropas indígenas del regimiento $\mathrm{n}^{\circ} 70$, que protegieron su retirada.

Por estas fechas las deserciones de las milicias filipinas eran constantes, como ocurrió con la mayor parte del tercio Anda Salazar, mandados por Buen Camino y con las fuerzas de Pío del Pilar, lo que provocó la ruptura de la línea defensiva Zapote-Bacoor. El repliegue de las fuerzas del coronel Lasala forzó a los defensores a permanecer dentro del perímetro de la ciudad con la excepción de los sectores de Santa Ana, San Juan del Monte y Santolan. Desde el instante que se rompió esta línea el cerco de Manila era una realidad,

22 A. Rodríguez, [13]. 
estando la plaza totalmente sitiada por tierra y mar y aislada del resto de la colonia. El sector central sufría al mismo tiempo muy duros ataques. El anciano fortín de San Antonio Abad pudo rechazar estos ataques, para luego los tagalos dirigir sus ataques contra las defensas de San Pedro Macatí y Santa Ana.

Lunes 6.

"Continúa el pánico en la población y la gente se teme cualquiera cosa de los insurrectos. Hay conflicto interior en el Gobierno. Dios nos ayude. Ha tomado el mando de las fuerzas y Gobierno de la plaza el general $2^{\circ}$ Cabo Sr. Jáudenes ${ }^{23}$. (...) Aumenta considerablemente el número de familias refugiadas en los bajos de la Escuela Normal calculándose en 1.200 las personas que pasan la noche allí. En el pórtico de aquella casa se establece todos los días un mercado de comestibles entre cuyos artículos figura la carne de perro cocida que se vende allí a buen precio. Ayer a las diez de la noche hubo mucho tiroteo en las cercanías de Sta. Ana. Dos balas que entraron en nuestra casa han sido hoy enviadas al R.P. Rector por el P. Vilallonga que con un H. guarda aquella casa. También hubo mucho fuego más allá del polvorín de S. Antonio. Todas las noches llueve mucho".

Martes 7.

"Los insurrectos están tenaces en pasar la línea de defensa. Anoche se hizo de una y otra parte un fuego atroz. El Capitán de Artillería Sr. Sendras no solo se ha defendido con valor sino que ha tomado la ofensiva. 200 hombres sitiados hace días por los insurrectos en $\mathrm{Ca}$ vite-viejo se han rendido al enemigo. Hace dias que nada se sabe del interior de la provincia".

Miércoles 8.

“(...) Esta noche pasada ha sido de gran tiroteo en la línea de defensa de la plaza. El Gral. Monet que con 3.000 hombres venía de

23 Resulta sorprendente esta noticia, ya que hasta agosto Augustín no fue relevado del mando. ¿Cómo es que da noticia que el $2^{\circ}$ Cabo se hace cargo del gobierno de la ciudad y del mando de las operaciones, estando el propio Capitán General en la plaza?. Otros testigos, Toral por ejemplo, narran como en todo el asedio a Augustín no se le vio por la ciudad ni en el frente, hechos que quizás permitan presumir que éste se encontraba por algún motivo incapacitado para el mando.

R. I., 1998, n. ${ }^{\circ} 213$ 
Zambales en socorro de la plaza, se ha visto obligado a fortificarse en S. Fernando de la Pampanga donde lo tienen encerrado 4.000 insurrectos número que aumenta todos los días. (...) Con la actividad desplegada por el Gral. Jáudenes se reanima un poco el espíritu público de Manila".

Jueves 9.

"La insurrección se extiende por Batangas y por algunas provincias del sur. Los españoles que se hallan en las provincias ocupadas por los insurrectos son llevados á Cavite viejo. (...) Háblase de una alianza entre España y Alemania no contra los yanquis sino contra los insurrectos".

Viernes 10.

"Persisten los insurrectos en forzar la línea de defensa pero inútilmente. La línea recibe todos los días refuerzos de cañones que se van sacando de la Maestranza y utilizando para la defensa. Hace algunos días se hacen secretamente gestiones con algunos cabecillas para arreglar con buena paz las discordias entre España y los indígenas. El Agente principal es el Cónsul de Bélgica”.

Domingo 12.

“(...) Por la tarde hay un gran incendio en el pueblo de Mandaloyan y son copados por nuestras tropas un centenar de insurrectos, que se habian hecho fuertes en la casa de las madres Agustinas".

\section{Lunes 13.}

“(...) Por la tarde un grupo de carabineros después de herir á un Sargento Peninsular y á un cabo, se han fugado, pero casi todos han sido muertos en la huida".

Este mismo día los sectores reformistas de la sociedad tagala se presentaron ante el Capitán General demandando la implantación inmediata de las reformas prometidas. Dicha comisión iba presidida por Pedro A. Paterno y por José Loyzaga. A la entrevista asistió el cónsul de Bélgica Andree. Augustín dijo que accedería a lo que solicitaban, la autonomía, siempre y cuando lograsen que los insurrectos depusiesen las armas. 


\section{Martes 14.}

"40 de los marineros hospedados en el Ateneo han sido incorporados al ejército regular de defensa de la plaza. El tiroteo de todas las noches ha sido menor estos últimos días".

\section{Miércoles 15.}

“(...) El río Lasing está obstruido en la barca de la laguna y sus orillas están llenas de trincheras enemigas. Se ha abierto una suscripción para comprar capotes impermeables para los soldados".

Jueves 16.

"Esta noche pasada ha arreciado mucho el tiroteo en la línea de defensa".

\section{Viernes 17.}

“(...) Por la absoluta incomunicación con que estamos por mar y tierra, los víveres van adquiriendo precios muy elevados. Los huevos de gallina se venden á 10 pesos el centenar, los plátanos á cuatro pesos, la carne de vaca a diez pesos la arroba".

\section{Domingo 19.}

"La noche pasada ha sido de muchísimo tiroteo en las avanzadas. Por el lado de S. Antonio Abad ha habido verdadero peligro pues hacía la madrugada han empezado á escasear las municiones en una trinchera defendida por 50 cazadores y se ha temido pasarán la línea los insurrectos. (...) Hace algunos días que sólo se habla de la escuadra que salió de Cádiz el 28 pasado, y sorprende algo que no se sepa positivamente que ha pasado el Canal de Suez. La gente da en decir que habrá tomado el rumbo del Cabo de Buena Esperanza. Esta versión hace sufrir bastante por lo mucho que retrasa las llegada de la escuadra, la que todos consideran hoy, como el único remedio que en los actuales apuros nos queda de tejas abajo. Hoy ha venido de Cavite doscientos enfermos y heridos españoles, á cada uno de los cuales Aguinaldo ha mandado dar un peso fuerte al despedirlos. Vienen los pobrecitos extenuados de hambre y quejándose de los malos tratos de que en Cavite son víctimas por parte de los indios los que están allí prisioneros".

\section{R. I., $1998, \mathrm{n}^{\circ} 213$}


Lunes 20.

“(...) Se espera con mucha ansia que nuestra escuadra llegue dentro de poco. Los yanquis han reunido toda su escuadra á la entrada del puerto de Cavite y han enviado á fuera al "Baltimore". Creése que por estar este barco muy averiado desde el $1^{\circ}$ de Mayo, lo resguardan los yanquis del próximo combate".

Miércoles 22.

"Desde la primera hora de la mañana hasta las doce se ha oído muchísimo tiroteo entre Bacoor y el río Zapote. Hay grandes esperanzas de que nuestra escuadra llegue muy pronto".

Sábado 25.

"Esta noche pasada ha sido grande el empeño de los insurrectos en pasar la línea".

Domingo 26.

“(...) Han logrado huir de la Pampanga acogiéndose á Manila la Señora é hijos del Capitán Gral. acompañado del anciano Padre del Coronel D. Eugenio Blanco. Han hecho el viaje en una barca sufriendo mucha hambre. También vino con ellos el general Monet á lo que parece contra la voluntad de aquella Señora. Ha producido mucho disgusto en Manila el abandono en que deja el Gral. a su gente"24.

Augustín ordenó a primeros de mayo al general Monet, comandante general del Centro y Norte de Luzón, que se retirase con sus fuerzas rumbo a Manila cuando la región ya se había sublevado. El 27 de mayo inició, con los efectivos que pudo agrupar de su brigada, la marcha en dirección a Manila, siendo atacado por numerosas

\footnotetext{
24 El ya citado Cónsul portugués narra así estos acontecimientos: "El general Augustín fue el primero en sorprenderse cuando tuvo conocimiento del feliz e inesperado arribo de aquellos seres tan queridos. Un sentimiento de profundo disgusto vino sin embargo a perturbar las gratas emociones que en aquellos momentos embargaban el ánimo del Capitán general de Filipinas: El general de brigada D. Ricardo Monet, Comandante general de las provincias del Centro de Luzón, había tenido el mal acuerdo de abandonar las fuerzas a sus órdenes, y vestido de paisano se vino en la misma embarcación de la Sra. de Augustín, dando lugar, según se dice, a que aquellas fuerzas, compuestas de un contingente de setecientos europeos, se desmoralizasen al juzgarse abandonados, $\mathrm{y}$, asaltando cuantas pequeñas embarcaciones encontraron a mano, embarcasen en ellas en la ilusión de poder llegar a Manila, cosa imposible una vez advertidos los americanos" citado por, A. R. RoDRIGUEZ [13].
} 
fuerzas rebeldes, por lo que se vio obligado a destacar pequeñas columnas para auxiliar pueblos sitiados y limpiar el camino de enemigos, realizando una marcha muy lenta y accidentada. Monet contaba con 700 hombres, teniendo que arrastrar una gran impedimenta compuesta por 50 heridos y numerosas familias peninsulares.

La columna Monet llegó a Macabebe, única plaza fiel aún a España en la región en aquellas fechas, para iniciar hacia Manila una marcha que se presentaba como muy difícil. Por tierra se presentaba como irrealizable, pues el asedio de la ciudad resultaba imposible de romper con las escasas fuerzas con que se contaba y especialmente dada la gran cantidad de heridos y civiles que tenía la columna. Por mar muy arriesgada, dado el control que la flota norteamericana tenía sobre las aguas de la bahía de Manila. Esta opción última fue la que se tomó. En el «Méndez Núñez» embarcaron los heridos, mujeres y niños enarbolando bandera de la Cruz Roja, el cual pudo llegar a Manila sin el menor contratiempo gracias a una densa niebla que le permitió entrar en el río Pasig sin ser localizado. Monet, por su parte, tomó una pequeña embarcación acompañado por la familia de capitán general Augustín logrando, a pesar de la mala situación del mar, llegar a la playa de Manila sin excesivos contratiempos.

La tropa montó en unos lanchones que serían remolcados por el «Leyte». El mando de la operación se dio al coronel Francia. La mala situación de la mar, así como las condiciones poco marineras de las lanchas - sin quilla y romas de popa - impidieron realizar con éxito su viaje. El «Leyte» temeroso de perder las barcas y con ellas a los hombres que iban de pasaje abandonó a éstas, quedando como jefe de las mismas el teniente coronel Dujiols. Entonces el «Leyte» se dirigió hacia los buques norteamericanos, izando el pabellón de parlamento, para recabar su ayuda. Se le acercó el «Concord» que le forzó a internarse en Cavite donde fue hecho prisionero sin respetarse la situación de tregua que le amparaba. Los lanchones quedaron a merced de un mar embravecido, siendo estos ingobernables al carecer de toda capacidad marinera. Dujiols y el capitán del «Arayat», alférez de navío Sostoa, tomaron una barquilla y se dirigieron a Manila, arribando a la playa de Tondo el 30 de junio, logrando que se enviase un vaporcillo mercante con víveres y socorro. Pero antes de que llegase el auxilio las barcas se estrellaron contra los esteros de Bulacán y Hagonoy, siendo capturados sus tripulantes por los tagalos.

R. I., $1998, \mathrm{n}^{\circ} 213$ 
Lunes 27.

"A las diez de la mañana los insurrectos han atacado desesperadamente la línea de defensa por el lado del fortín de S. Antonio pero han sido rechazados. Cinco balas han caído en la Escuela Normal y dos de las mujeres allí reunidas han resultado heridas. Es caso frecuente caer alguna bala en dicha casa todas las veces que hay algún ataque fuerte. Los desvelos de los Superiores logran hacer casi insensible la creciente escasez de víveres que hay en Manila. Todas las privaciones se reducen a comer carne de carabao en vez de vaca, y á la abstención de pescado fresco, puspás, huevos y leche frescos, frutas y verduras todo lo cual se suple ó con provisiones de laterías o de otra manera".

Miércoles 29.

"Esta tarde ha salido de la Pampanga el cañonero "Leyte" dirigiéndose á un barco yanqui que ha salido á recibirlo, y después de un rato de conferencia ha continuado su marcha hacia los barcos yanquis arriando la bandera española é izando la yanqui".

Jueves 30 de Junio.

"Entran en la bahía cinco barcos yanquis, el "Baltimore" y el "Charleston" con tres transportes y 2.500 hombres de desembarco. Créese que han pasado por Marianas apoderándose de las islas y que traen prisionero al gobernador. El Teniente Coronel Sr. Dujiols, ha venido por mar huyendo de la Pampanga con 16 ó 17 hombres con grandes dificultades y peligros. Las tropas que estaban en la Pampanga con el Gral. Monet, se han dispersado acosadas por los insurrectos. La mayor parte de los soldados han caído prisioneros, otros han porfiado á venir por mar y de alguna se dice que se están defendiendo en destacamentos aislados".

A mediados de junio llegaron las dos primeras expediciones de infantería norteamericana, permaneciendo dichas fuerzas a la espera de más efectivos y material antes de entrar en fuego. La brigada Anderson desembarcó en Maytubig donde acampó, lista para operar contra las trincheras españolas de San Antonio Abad. Situándose otras fuerzas en Cavite y en la costa de Parañaque. Thomas M. Anderson, brigadier general de voluntarios, ejerció el mando de las tropas norteamericanas hasta la llegada del general Wesley Merritt.

R. I., 1998, n. ${ }^{\circ} 213$ 
Viernes 1 de Julio.

“(...) Ha habido una fuerte acción en San Juan del Monte. Dicese que los nuestros sin baja alguna han matado al cabecilla Montenegro y á unos 200 insurrectos. (...) Circula por Manila una carta del Teniente Coronel Buencamino al Gral. en que él se declara Filibustero y enemigo de España".

\section{Sábado 2.}

"Por haber abandonado nuestras tropas las máquinas que en Santólan recogen para la población el agua de Carriedo, no podrán los depósitos dar abasto de agua para todo el día, por lo que en adelante las cañerías solamente manarán desde las 8 á las 12 del día. Después de la llegada de los refuerzos yanquis se ha estrechado más el bloqueo de Manila. Muchas personas tenían autorización para salir por mar de Manila, y no se sabe si podrán lograrlo. (...) Dicese que las tropas yanquis han venido á ocupar Manila, no á conquistarla, por lo que Dewey ha enviado el "Zafiro" á Hong Kong á buscar órdenes de su gobierno".

Volviendo al documento del citado cónsul portugués, éste cuenta de la siguiente forma estos mismos sucesos: "Coincidiendo con estos acontecimientos, dieron los rebeldes que guarnecen la orilla derecha del Pasig, reforzados con otros de los pueblos limítrofes, un rudo ataque al caserío de Santolán, donde se encuentran las máquinas elevadoras de agua que surten a la ciudad de Manila, y aun cuando fueron rechazados por el destacamento español allí establecido, quedó éste en una situación tan crítica y comprometida, que hizo necesario la salida de esta Capital de una columna del ejército para salvar a los soldados, teniendo que abandonar aquella posición aùn a trueque de que con la destrucción de las máquinas privasen a Manila del servicio de aguas, contratiempo éste, si bien era muy sensible, no habría de influir en el resultado de los acontecimientos en la guerra, porque además de las aguas del río Pasig, tiene Manila pozos y aljibes suficientes para surtir a la población durante mucho tiempo"25.

\footnotetext{
25 Idem.
}

R. I., 1998, n. ${ }^{\circ} 213$ 
Domingo 3.

"Para evitar en lo posible los abusos en las ventas de comestibles, ha salido un decreto fijando el precio de los artículos de almacén de comer, beber y arder. Ha sido recompuesta la línea férrea desde Dagupán hasta Caloocan. (...) Ha venido de Cavite el Coronel D. Eugenio Blanco que cayó prisionero de los yanquis a bordo del Cañonero "Leyte". Viene a tratar con el Gral. asuntos de importancia" 26.

El citado decreto decía: Artículo $1^{\circ}$.- Los productores, acaparadores y comerciantes que en el plazo que prefije la Comisión civil de defensa no suministren a ésta los datos que reclame sobre las existencias y precios de las mercancías que posean, incurrirán en la multa de 500 a 5.000 pesos; Artículo $2^{\circ}$.- La comisión civil de defensa, en vista de los datos que adquiera, señalará los pæecios a que han de expenderse, en la plaza y sus arrabales, los comestibles, bebidas, productos farmacéuticos, calzado y vestuario preciso, y cualesquiera otros artículos de primera necesidad; Artículo $3^{\circ}$.- Los que expendan artículos de los numerados a mayor precio que el señalado por dicha Comisión, y los que alteren el peso o la medida legal de los mismos, incurrirán en la multa de 100 a 1.000 pesos; Artículo $4^{\circ}$.- Las multas a que se refiere los artículos $1^{\circ}$ y $3^{\circ}$ se impondrán y se harán efectivas por la Comisión civil de defensa, y su importe se aplicará por mi autoridad a mejorar la alimentación de las tropas o al gasto de la guerra; $5^{\circ}$.- La Comisión civil de defensa, por delegación de mi autoridad se incautará de las existencias indispensables para satisfacer las necesidades de la plaza, siempre que con cualquier motivo o pretexto se nieguen a facilitarlas sus poseedores, ya sean éstos asentistas del Ejército o la Armada, abastecedores de los establecimientos benéficos, comerciantes, corporaciones o particulares;

26 El citado informe consular cuenta a este respecto: "A fin de prevenir las contingencias a que pudiera dar lugar la cuestión de alimentos si se prolongaba el bloqueo de la plaza por la escuadra norteamericana y el asedio de los insurgentes, el Gobernador general dispuso la creación de Junta civil de defensa, de la cual forman parte el Excmo. y Rvdmo. Sr. Arzobispo metropolitano, el Alcalde de la Ciudad, el Gobernador civil de la provincia y el Secretario del Gobierno Central, adoptando como primera providencia la adquisición de grandes cantidades de arroz, puesto que este grano viene a constituir el principal y hasta casi puede decirse el único alimento de la clase proletaria de este país. Pero de tal manera despertó la codicia de algunos mercaderes sin conciencia el actual estado de cosas, que hubo necesidad de tomar medidas preventivas para impedir que continuara el alza constante en los artículos alimenticios, y por el Capitán general y General en jefe del Ejército en operaciones se dictó un bando". 
$6^{\circ}$.- Al verificar la incautación que consigna el artículo anterior, la Comisión civil de defensa expedirá al dueño de las mercancías el correspondiente resguardo por valor de las mismas, contra Hacienda; $7^{\circ}$.- Los que expendan bebidas o comestibles averiados o adulterados serán juzgados en Consejo de Guerra, o sufrirán la pena que les corresponda.

La situación de la plaza era cada día más preocupante, pensemos en el número altísimo de personas en ella refugiados y la dificultad que suponía cubrir sus necesidades diarias en materia alimenticia. Las autoridades de Manila son dignas de encomio en su labor, pues la población nunca llegó a padecer serias privaciones durante el largo asedio, hecho que no implica que la situación fuese verdaderamente preocupante. Juan y José Toral la describen en los siguiente términos "Cada día va en aumento el abuso de los comerciantes, y no se cómo se las arreglarán las muchas familias que aquí hay con pocos recursos para no morir de hambre. Están ya casi agotadas las existencias que tenían los almacenes de víveres de Europa, los cuales han dado salida a todos los géneros antiguos y averiados; los pocos que quedan se ocultan cuidadosamente, y sólo se venden al que los paga en cinco o seis veces su valor. El mercado de víveres frescos está también exhausto, porque los insurrectos impiden a los naturales que pasen de nuestras líneas con ningún comestible, y si por casualidad se encuentra algo, sólo pueden comprarlo los que tienen bastantes recursos. Un huevo, cuando lo hay, cuesta 12 céntimos de peso, y un pollo o pescado, dos o tres pesos; se carece de harina, y estamos comiendo ya carne de carabao"27.

Lunes 4.

"Asegúrase como cosa cierta que la escuadra de Cervera viene á nuestro socorro y que el día 12 de Junio se encontraba haciendo carbón en la isla Mauricio".

Martes 5.

“(...) Sábese que viene una $2^{a}$ expedición de yanquis que salió de $S$. Fran. de California el 17 del pasado".

27 J. y J. TORAL, [7], p. 146.

R.I., $1998, \mathrm{n}^{\circ} 213$ 
Miércoles 6.

“(...) Es esperada con ansia la escuadra española del contra almirante Sr. Cámara, la que según dicen pasó el 28 último por la isla de Seering en el estrecho de Bad-el-mandel. (...) Parece que Aguinaldo ha recibido de la junta revolucionaria de Hong Kong presidida por Agoncillo (el viejo) orden de rescindir el contrato hecho con los yanquis, pues ha sabido aquella junta que los Estados Unidos preparan para Filipinas una grande expedición de inmigrantes que tienen ya constituído el Sindicato azucarero y abacalero para explotar en beneficio propio el comercio de aquí".

Jueves 7.

"El tiroteo ha sido muy grande la noche pasada. Cerca de 200 voluntarios que ocupaban una trinchera próxima á Sta. Ana se han pasado al enemigo, dicen que quejosos de que no se les pagaba con puntualidad. Providencialmente no hemos tenido una sola baja, mientras que los traidores cogidos entre dos fuegos, han tenido muchísimas".

Sobre este gran ataque realizado el día 6 dice Jesús Álvarez Pérez, el ya citado cónsul de Portugal: "Reforzadas las líneas de defensa enemigas con fuerzas de refresco traídas de las demás provincias levantadas en armas, y contando con la traición de algunas tropas indígenas de las que se hallaban defendiendo las trincheras, intentaron los rebeldes un formidable ataque a la línea exterior de defensa en la noche del 6 de Julio, que sin el valor y el arrojo del soldado español, seguramente les hubiera valido una victoria: Ciento noventa hombres de tropas indígenas, de acuerdo con los rebeldes, y después de empeñado el combate, abandonaron su puesto, prestando no sólo el concurso de sus armas al enemigo, sino dejando abandonada una gran extensión de terreno por donde hubieran penetrado los insurrectos, si los oficiales, apercibidos a tiempo, no hubieran cubierto inmediatamente las trincheras, y sin el acierto de la artillería que, a pesar de la lluvia pudo, con sus certeros disparos, hacerles innumerables bajas, sembrando la muerte y el desconcierto entre las filas enemigas" 28 .

28 A. R. RODRIGUEZ, [13]. 
Viernes 8 .

"Dicese que Aguinaldo trata de entregar los prisioneros españoles que tiene en su poder, porque son para él un estorbo y quizás porque los teme. A esto obedecen las idas y venidas que desde el Domingo pasado hace de Manila á Cavite D. Eugenio Blanco. Ha llegado un Vapor mercante francés á buscar á varias personas de Manila que tienen tomado pasaje para España. El Comodoro Dewey, se ha llevado dicho vapor al fondeadero de Cavite y ha impedido que embarcara en el persona alguna. Dicese que para este proyectado viaje había concedido licencia más o menos explícita el mismo Dewey por lo que su actitud ha motivado disgustos y protestas del Cónsul francés".

Domingo 10.

"Llegan á Cavite los tres barcos yanquis que salieron hace cinco días. Fueron á Olongapo á intimar la rendición á 600 soldados españoles que alli había. Aunque se hace correr con insistencia la noticia de que ellos, habiendo recibido provisiones de un barco alemán y otro japonés, se han resistido con valor, es lo cierto que se han entregado al enemigo y que están en Cavite prisioneros de los yanquis. (...) Corre la noticia de que Aguinaldo ha tenido algunas diferencias con el Comodoro, quién le ha puesto preso proclamando Dictador á Gregorio Rianzares".

\section{Jueves 14.}

"Hace tres días que hay completo silencio en la línea de defensa de día y de noche. Circulan noticias muy variadas sobre la escuadra de Cámara y Cervera que muchos suponen viene para acá. (...) De Aguinaldo sabemos por conducto fidedigno que ha abandonado á Cavite y se ha instalado en Bacoor, para sustraerse á la continua vigilancia de los yanquis que so pretexto de visitarle lo tenían sitiado todo el día. Añadase a esto que él supo que deseosos los yanquis de acabar con él tenían ya señalado el sujeto que debía asesinarle".

Viernes 15.

“(...) Esta mañana ha sido atacada con mucho brío toda la línea de defensa en la que hemos tenido 20 bajas. En la Normal ha sido he-

R. I., 1998, n. ${ }^{\circ} 213$ 
rido un hombre, y otras cuatro personas en las cercanías. Dícese que los yanquis que han atacado han tenido muchas bajas".

Sábado 16.

"Llega un gran barco yanqui de 4 palos trayendo gente de refuer$z o "$.

Domingo 17.

"Precedido por el "Boston" que salió hace tres días, han entrado en bahía tres grandes barcos mercantes llenos de yanquis. (...) Otro ataque han vuelto á dar los insurrectos sin resultado. (...) La población ya no recibe agua de Carriedo, pero Dios acude solícito á la necesidad enviando lluvias abundantes, que además de llenar los aljibes de las casas refrescan la atmósfera y nos preservan de las enfermedades que nos traía otros años el excesivo calor".

Lunes 18.

"Habiendo pasado la guardia civil veterana á hacer requisa de los caballos que los particulares pudiesen ofrecer para las actuales necesidades el R.P. Rector del Ateneo ha cedido dos. El barco japonés llegado ayer, ha traído noticias tristes. La escuadra de Cervera echada á pique por los yanquis y Santiago de Cuba en poder del enemigo".

Miércoles 20.

"Sábese en Manila con absoluta certeza aunque no es público, que la escuadra de Cámara ha recibido orden de volver á España. (...) Desde anteayer está el "Boston" junto á Parañaque protegiendo el desembarco y acampamiento de tropas yanquis en aquella playa. Es de temer que preparen ataque formal por aquel lado".

La Escuadra de Reserva del almirante Cámara, cuyas fuerzas principales eran el acorazado «Pelayo», el crucero acorazado «Carlos V» y tres cruceros auxiliares «Rápido», «Patriota» y «Buenos Aires», partió en socorro de las Filipinas. El 26 de junio llegaba a Port Said, y tras muchos problemas materiales y diplomáticos con las autoridades británicas que habían adoptado una neutralidad claramente inclinada en favor de Washington, la escuadra logró cruzar el Canal. Era el día 4 de julio, pero la derrota de Cervera el 3 en 
Santiago de Cuba decide al gobierno de Madrid a ordenar el regreso de Cámara ante un posible ataque yanqui a las Canarias o a las costas españolas. El 10 de julio la escuadra está otra vez en Port Said tras desandar el camino hecho. Las Filipinas han sido abandonadas a su propia suerte.

Jueves 21 .

“(...) Esta noche pasada han atacado por Sta. Ana los insurrectos, apoyados según se dice por los yanquis á retaguardia. Parece que nuestras fuerzas han hecho muchos disparos de cañón sobre la retaguardia enemiga".

\section{Viernes 22.}

"Hoy se ha abandonado una trinchera muy avanzada de dificil defensa próxima a S. Pedro Macati. De resultas del abandono entre 7 y 8 de la noche ha habido en toda la línea un tiroteo espantoso. El estampido del cañón era continuo. Dicen que nosotros hemos tenido 30 bajas en toda la línea, y muchas el enemigo. (...) Hace muchos días que para proveer de carne á la población, anda la Veterana arramblando con todos los carabaos de los particulares sin avisar á nadie".

\section{Sábado 23.}

"Anoche hubo en las trincheras un ataque más que regular. (...) la correspondencia que ha traído el "Cormoran" (vapor alemán) viene llena de malas noticias, entre otras la de que es cierta la toma de Santiago de Cuba por los yanquis y que entre las condiciones de paz, figura la libertad de Cuba y anexión á los Estados Unidos de Puerto Rico y Marianas. El caimiento de ánimo que las tales noticias producen es grande".

Domingo 24.

"Entre 11 y 12 de la mañana han caído intramuros 4 ó 5 granadas disparadas por el lado de Malate. Gracias a Dios no han causado desgracia alguna".

Lunes 25.

"A medio día ha fondeado en bahía un barco mercante que según dicen trae á bordo al Gral. Merrit. Corren noticias alarmantes so-

R. I., 1998, n. 213 
bre la situación interior de España: que de un motín ha escapado herido Primo de Rivera huyéndose á Francia con Moret, Maura á Portugal, etc, etc".

\section{Martes 26.}

"Esta noche pasada por el lado de S. Antonio Abad ha habido tiroteo breve pero intenso. Han matado al Teniente Ojeda del batallón $n^{\circ} 4$ de Cazadores. (...) Continúan circulando noticias alarmantes sobre la situación interior de España, y se dice que el populacho ha asaltado nuestra residencia de Talavera y un Covento de Dominicos y otro de Agustinos".

Miércoles 27.

“(...) La noche pasada ha sido grande el ruido de cañonazos en la línea de defensa. El "Pascal" va á Cavite á saludar á los yanquis. Un oficial del "Pascal", antiguo discípulo nuestro, nos ha dicho que probablemente Dewey intimará la rendición de la plaza antes de ocho días. La carne de carabao escasea ya mucho".

Viernes 29.

"Otra vez se han oído tiros en Cavite á la misma hora que ayer. La uniformidad en las horas hace creer que el tal ruido de tiros es ejercicio de tiro. En todo el día de ayer y la noche de pasada no se ha oído un solo tiro en las líneas de defensa. Es más; en algunos puntos se han juntado cabecillas insurrectos, con oficiales nuestros á comer juntos gallinas y otros manjares que escasean mucho en Manila".

Domingo 31 de Julio, Fiesta de N.P.S. Ignacio.

“(...) Por la tarde han entrado 5 barcos mercantes llenos de tropas yanquis. Con los llegados hoy serán ya doce ó catorce mil los soldados yanquis dispuestos á atacar á Manila. Dicese que el Vapor mercante yanqui "City of Pekín" que ayer salió para S. Fran. de California, llevaba muchos soldados enfermos".

Los ataques durante la primera quincena de julio siguieron siendo continuados y llevados a cabo únicamente por los tagalos, uniendo ya a su continuo fuego de fusilería el realizado por algunas piezas de artillería: un cañón de $80 \mathrm{~mm}$ y tres de $160 \mathrm{~mm}$ junto a diversos cañones de pequeño calibre. Los combates más duros fueron en el 
sector centro y el derecho - blocaos 13,14 y 15 , y sus trincheras intermedias-; así como en la zona de San Juan del Monte y Santa Ana, también asaltaron con brío el barrio de Mandalayon que fue defendido con éxito por el general Rizzo, estando varias veces a punto de romper la línea los tagalos por el blocao 9.

El día 22 de julio por primera vez se notó la presencia de tropas americanas frente a las posiciones españolas, aunque con el único objetivo de que se fuesen fogueando. La presencia de estos hizo que los ataques filipinos aumentasen, intentado, por dos veces consecutivas, romper la línea por San Pedro Macatí, para luego intentarlo por la zona donde los atrincheramientos eran más débiles, entre Santa Ana y la Concordia, cuyo punto era la parte comprendida entre el camino de San Pedro Macati y el blocao 11.

Durante el día 26 hubo fuertes combates entre San Antonio Abad y el blocao 14, donde las fuerzas del batallón $\mathrm{n}^{\circ} 4$ de cazadores, junto con los restos de las fuerzas de los voluntarios de Anda Salazar y de otras unidades de cazadores de la columna Dujiols lograron forzar en la madrugada del 27 la retirada de los tagalos que casi habían logrado abrir una brecha en las trincheras españolas.

El día 30 los tagalos asaltaron una vez más con gran vigor el blocao 1, así como las trincheras situadas entre el 3 y 4 . Igualmente en el sector derecho atacaron con desesperación los blocaos 13 y 15 . El día 31 los norteamericanos tenían ya reunidas y preparadas sus fuerzas para comenzar el asedio y asalto de Manila. El día 1 de agosto los tagalos redoblaron con más ímpetu, si cabe, sus ataques. Este día ya combatieron fuerzas norteamericanas de los regimientos Oregón y Pensilvania frente a las posiciones españolas de San Antonio Abad. Tuvieron entre 25 y 30 bajas, entre ellos un capitán del Oregón y un teniente del Pensilvania.

Lunes 1 de Agosto.

"Desde las 11 y media de la noche hasta la una de la madrugada ha habido en la línea de defensa desde S. Antonio á Mandaloyan el tiroteo más estrepitoso que se ha oído en estas islas desde que hay yanquis en ellas. Cañones, ametralladoras y fusiles jugaban á porfia sin cesar de una y otra parte. Mucha gente de la Ermita ha huido de sus casas refugiándose en la Escuela Normal donde han pasado la noche más de 2.000 personas. Han reventado muchas granadas de procedencia yanqui en toda la esplanada que hay desde la ciudad

R. I., $1998, \mathrm{n}^{\circ} 213$ 
murada hasta el campo de batalla: una granada ha estallado en una sala del Cuartel de la Luneta y ha matado á tres soldados y herido á diez; otra en el Puente de España matando un caballo; otra en la Ermita matando un muchacho y un hombre. Otras muchas han caído en diversas partes sin causar desgracias. En nuestra casa de Sta. Ana han estallado dos, disparadas desde Mandaloyan y en la huerta de la Escuela Normal tres, sin causar, á Dios Gracias, ningún daño personal. Una de estas últimas ha reventado en la huerta, y un casco ha entrado en el cuarto del R.P. Superior, dormitorio actual del $P$. Algué y ha destrozado la ventana con gran espanto del P. Algué y de algunos hermanos que estaban observando desde la ventana contigua. El P. Algué acababa de salir de su dormitorio por providencia de Dios. En las trincheras hemos tenido un muerto y siete heridos. Los cascos de granada recogidos en el Observatorio llevan la marca de un Arsenal de los Estados Unidos".

Martes 2.

"Parece ha dicho Dewey que hasta el día 13 del actual no tendrá las tropas en disposición de tomar la plaza de Manila. Anoche hubo en las trincheras un ataque intenso como el de ayer, pero que duró poco. Cayó alguna granada en la Normal. Pero sin causar desgracias".

Miércoles 3.

"Parece se nota en el campo insurrecto simpatía por España. El cabecilla Pío del Pilar se ha ofrecido á traer víveres vendiéndonos vacas y carabaos. Recíbese en Manila la noticia de haber caído Dagúpan en poder de los insurrectos el día 30 pasado. 700 hombres que se habían defendido largo tiempo en dicho pueblo se entregaron al enemigo con armas y bagajes. La carestía de víveres aumenta cada día en Manila. Mátase todos los días algunos caballos y su carne se vende al precio de la de carabao. El pan es el artículo cuya escasez se deja sentir más: mucha gente no lo come hace días. Lo venden tasado y á buen precio".

En estas fechas las fuerzas de Aguinaldo desconfiaban ya de las verdaderas intenciones de los norteamericanos. Pío del Pilar, general de una de las partidas insurrecta y antes uno de los más exaltados voluntarios de la milicia, escribía al capitán español Acevedo unos día antes de la venta del ganado: "Sr. D. F. Acevedo.- Macati, 30 de 
julio de 1898.- Mi carísimo amigo: Participo a usted que ayer fui a conferenciar con mi jefe don Emilio Aguinaldo, y me dijo que el lunes 2 entrante mes de Agosto empezarán los ataques contra ustedes de los americanos sin falta; por este motivo, encarga mi referido jefe le entere a usted y a todos los que se cobijan bajo la bandera española, de que no tenga miedo y no se desanime, sino que, al contrario, fortalezcan vuestros corazones en vuestra pelea y háganse fuertes bien y no retrocedan ante sus cañones. Asimismo, si, por ejemplo, concentran ustedes todas las fuerzas en Manila y abandonan Santa Ana, y sea posible cederlo a mí, yo me estableceré allí con mi Ejército.- Pío del Pilar"29. Aguinaldo y sus jefes principales tenían pruebas fiables de cual iba a ser su futuro, estando dispuestos a pactar incluso con el mismo diablo para no perder todo el esfuerzo realizado.

\section{Viernes 5.}

"Durante la noche pasada no se ha oído un solo disparo, gracias á los chubascos y ventolinas que el baguio nos regala. A las 7 de la mañana ha habido media hora de tiroteo. (...) Con general sorpresa ha sido destituido el Capitán Gral. D. Basilio Augustín. Parece que ha motivado esta resolución del Gobierno un telegrama del Gral. en el cual declaraba que, puesto que no viene la escuadra de Cámara, el declina toda la responsabilidad que pueda recaer sobre él del éxito de la guerra ${ }^{30}$. El Gral. ha reunido junta de Autoridades y delante de ellos ha hecho manifiesta la orden del Gobierno entregando luego el mando al Gral. de División D. Fermín Jáudenes. En lugar de este ha sido nombrado $2^{\circ}$ cabo el Gral. Rizzo. Se han re-

29 M. SASTRON, [16], p. 484.

30 El ya varias veces citado documento estudiado por A. R. Rodríguez y escrito por el cónsul portugués en Manila dice en relación a este suceso: "En estas condiciones se recibió el 4 de Agosto un telegrama del gobierno español, fechado el 27 de mes anterior, en el que, contestando a otro del general Augustín, que había lamentado el retraso de la escuadra del general Cámara y declinado en el gobierno la responsabilidad de los acontecimientos futuros, se le prevenía que entregara el mando al $2^{\circ}$ Cabo, general Jáudenes. Gran asombro causó en la opinión pública esta decisión del gobierno español, reaccionando en favor del mencionado general Augustín (que no gozaba de las mayores simpatías entre el elemento peninsular aquí residente) no faltando suspicaces que a este cambio de autoridades achacasen la comunicación dirigida dos o tres días después por el general Wesley Merritt y Comodoro Dewey al general Jáudenes, participándoles que, cumplidas cuarenta y ocho horas del recibo de aquella comunicación, romperían el fuego por mar y tierra hasta rendir la plaza, lo cual se le comunicaba para su conocimiento y a su fin de que pusiera en salvo, si lo estimaba conveniente, a las mujeres, niños, ancianos, enfermos, etc, para evitar el mayor número de víctimas posible".

R. I., 1998, n. $^{\circ} 213$ 
partido cartas y periódicos que dan como seguras la siguientes condiciones de paz que está para firmase entre España y los Estados Unidos: $1^{a}$ Independencia de Cuba. $2^{a}$ Anexión de Puerto Rico y Marianas. Añádese que España está dispuesta á firmar esta paz con tal que los Estados Unidos ó Cuba libre, reconozcan la deuda que pesa sobre esta isla á lo cual se niegan los yanquis".

Sábado 6.

"Han entrado en la población algunas vacas que ha dejado pasar Pío del Pilar al precio de 200 pesos una. En tiempo de paz el precio de las vacas oscilaba entre 20 y 30 pesos una. Esta noche los yanquis han tenido grande iluminación de focos eléctricos, pues jugaban con 6 ó 7 á la vez".

\section{Domingo 7.}

"Esta mañana les ha llegado a los yanquis un barco mercante con bandera inglesa que parece traía pliegos oficiales del Gobierno de Wasington (sic). A las 12 horas visita al Gral. el Vice Cónsul inglés y el Cónsul Belga. Traía el Cónsul inglés un pliego firmado por Dewey y Merrit, cuyo contenido era poco más o menos el siguiente: pudiera ser que dentro de 48 horas atacáramos la plaza por mar y tierra. Se lo decimos a usted con esta anticipación para que tenga tiempo de poner á salvo la gente indefensa. El Gral. ha contestado á los yanquis que bien sabían ellos que no podía sacar de la plaza á la gente indefensa por estar los insurrectos casi á las puertas de Manila. El Cónsul Belga que traía en el bolsillo las condiciones de la capitulación por si el Gral. hubiese deseado conocerlas, se las ha guardado sin decir palabra al oír la respuesta de este. La noticia del próximo bombardeo ha corrido como un rayo por la ciudad, y toda la gente se ha aprestado como podía á la defensa. Los militares no descansan un momento acarreando carros de pólvora y balas de cañón y aprestos de guerra.".

El día 7 de agosto los norteamericanos intimaron a la rendición de la ciudad con una carta cuyo texto decía:

"Cuartel general de los Ejércitos de mar y tierra de los Estados Unidos.- 7 de Agosto de 1898.- Al general en jefe Comandante de las fuerzas españolas en Manila.- Señor: Tenemos el honor de manifestar a 
V.E. que las operaciones de las fuerzas marítimas y terrestres de los Estados Unidos contra las defensas de Manila podrán empezar en cualquier hora después de la expiración del plazo de cuarenta y ocho horas, contadas desde la en que V.E. reciba esta comunicación, o antes, si fuese necesario, por motivo de cualquier ataque por vuestra parte.- Esta notificación se da para que V.E. tenga una oportunidad de mandar salir de la plaza elemento no combatiente.- Firmado Werley Merritt, Mayor general del ejército de los Estados Unidos.- George Dewey, contralmirante de la Marina de los Estados Unidos, comandante de las fuerzas marítimas de los Estados Unidos en la estación asiática".

A esta misiva contestó Jáudenes:

"El Gobernador general y Capitán general de Filipinas.- Manila, 7 de agosto de 1898.- Al Mayor general del Ejército y al contralmirante de la Armada, comandantes respectivamente de las fuerzas de tierra y mar de los Estados Unidos.- Señores: Tengo el honor de participar a SS.EE. que a las doce y media del día de hoy he recibido la notificación que se sirven hacerme de que, pasado el plazo de cuarenta y ocho horas, pueden comenzar las operaciones contra esta plaza, o más pronto si las fuerzas de su mando fuesen atacadas por las mías.- Como su aviso es dado con objeto de poner a salvo las personas no combatientes, doy a SS.EE las gracias por los sentimientos humanitarios que han demostrado y que no puedo utilizar, porque, hallándome sitiado por fuerzas insurrectas, carezco de punto de evacuación adonde refugiar el crecido número de heridos, enfermos, mujeres y niños que se hallan albergados dentro de las murallas.- Muy respetuosamente B.L.M. a SS.EE., Fermín Jáudenes, Gobernador general y Capitán general de Filipinas"31.

A estas dos cartas siguió un intercambio de notas en la cual los jefes norteamericanos solicitaban nuevamente la rendición. Jáudenes pidió que le autorizasen consultar con su gobierno por medio del telégrafo de Hong Kong, a lo que se negaron los norteamericanos. La única alternativa para los españoles era resistir.

\section{Lunes 8.}

"Con una ansiedad parecida á la del reo en capilla, es esperado por todos el día de mañana. Muchas señoras se embarcan á pesar del mucho oleaje que hay en la bahía. El Gral. publica un bando dando órdenes oportunas para la defensa de la plaza y señalando

31 M. SASTRON, [16], pp. 487y 488.

R. I., $1998, \mathrm{n}^{\circ} 213$ 
sitios de refugio durante el bombardeo á la gente de la cuatro zonas en que según el bando queda desde hoy dividida la ciudad murada, prohibe andar en coche excepto á los médicos, á los sacerdotes que lleven el Stmo. Sacramento y algunas de las primeras autoridades. (...) Parece que el Gral. ha pedido á los yanquis 6 días de plazo para consultar al Gobierno sobre la situación actual y los yanquis no han accedido, extrañándoles mucho que no tenga el general facultades suficientes para obrar por si y sin necesidad de consultar al Gobierno".

Martes 9.

"No hemos sido bombardeados como nos temíamos. Ha dicho (R. P. Superior) que era seguro que veríamos arriar la bandera Española é izar la yanqui (...). La bahía se ha despejado durante la mañana, dirigiéndose unos barcos á Mariveles, otros á Bulacán y otros á Cavite. Dos barcos yanquis, el "Mc.Culloc" y el "Concord" se han puesto de guardia frente á la bocana del río. Hoy y ayer se han celebrado bajo la presidencia del Capitán Gral. juntas de autoridades $y$ de Generales. Se han abandonado las trincheras de S. Juan del Monte retirándose las avanzadas a Sta. Mesa. Las calles de la ciudad están desiertas; solo se ven en ellas soldados, chinos y batas".

Miércoles 10.

"En todas las notas que han pasado los yanquis al Capitán Gral. estos días pasados, ha dominado la idea de suplicar al Gral. que capitule para evitar los efectos desastrosos del bombardeo. (...) Las noticias de estas súplicas de los yanquis parece que levanta algo el abatido espíritu de la gente, pues algunos hay que dos días atrás optaban por la rendición á quienes ya les parece mejor la resistencia. No ha habido bombardeo, gracias a Dios. (...) Las trincheras insurrectas que rodean á Manila están coronadas de banderas blancas. Los P.P. Clotet y Martínez que han ido á Sta. Ana, han sido testigos del amigable consorcio en que viven leales é insurrectos por aquel lado".

Jueves 11.

"A los yanquis parece que se les ha pasado las ganas de cumplir sus amenazas pues en todo el día no se han movido de sus puestos. (...) 
Dícese que el entorpecimiento en las operaciones se debe á las lluvias torrenciales que han inundado los campos por donde han de atacar los yanquis. Reina mucha paz en las líneas de defensa de noche y de día".

\section{Viernes 12.}

“(...) Todo sigue con gran tranquilidad y aún hay quién dice que es imposible un bombardeo desde el momento que las potencias Europeas reunidas en Berlín han declarado que se opondrían á la anexión de Filipinas á los Estados Unidos".

\section{Sábado 13.}

"Hoy la plaza de Manila se ha rendido a los yanquis. Las primeras horas del día no anunciaban novedad alguna. (...) De repente se ha puesto en movimiento toda la escuadra yanqui. Los Vapores que estaban de guardia han ido á reunirse con los demás y se han dirigido hacia el fortín de S. Antonio. Cuatro barcos grandes que debían de ser el "Olympia", el "Boston", el "Raleig" y el "Baltimore" han cañoneado aquel fortín. Luego la han emprendido contra las trincheras perpendiculares á la línea de la playa, jugando el principal papel en el ataque un Cañonero que debía de ser el "Leyte" ó el "Callao". En medio del cañoneo ha sobrevenido un fuerte chubasco que nada ha estorbado el ataque. A las cinco cuartos de hora de fuego han juzgado los Yanquis que el campo estaría completamente despejado, por lo cual han suspendido el fuego de los barcos empezando á marchar el ejército de tierra en formación hacia Manila. Nuestras tropas agazapadas en las trincheras que aún quedaban, han sorprendido con dos rociadas de balas á los yanquis que entraban con toda seguridad y que se han quedado parados. En esto el "Olympia" y el Monitor "Monterey" se habían colocado frente á Manila, y este último tenía sus cañones de 30'5 centímetros apuntando á la batería de dos cañones de La Luneta. Ha disparado el "Olympia" un cañonazo sobre nuestras trincheras cuyos soldados han recibido luego orden de retirarse mientras sobre las murallas de la Ciudad se levantaba una gran bandera blanca. La plaza, llena como estaba de gente indefensa, no ha hecho fuego sobre los barcos por no atraer sobre sí las balas enemigas. Ha habido parla-

R. I., $1998, \mathrm{n}^{\circ} 213$ 
mento en el cual parece que los Yanquis se han mostrado generosos en todas las condiciones, con tal que se les entregue la plaza ${ }^{32}$.

Los insurrectos han estado á la mira con ánimo de sacar todo el partido posible de nuestra desgracia. La amistad que mostraban estos últimos días, era la simpatía que por el rico moribundo sienten sus domésticos quienes procuran apoderarse de sus riquezas, antes que de fuera venga otro á tomárselas. Un poco antes que los Yanquis han atacado ellos las trincheras y luego han entrado por la brecha que han dejado abierta nuestras tropas al retirarse. La Vanguardia Yanqui que iba á preparar sitio á los demás se ha dirigido al Observatorio...

La brigada de Greene, seguida de la de Mac-Arthur, es decir la división Anderson al completo, se infiltró por las líneas ocupando nuestras posiciones aprovechando la tregua. La brigada Greene atravesó el barrio Malate, la Ermita y los puentes, ocupando finalmente el barrio de Binondo y de San Miguel. La de Mac-Arthur tomó posiciones en los barrios que las fuerzas de Greene acababan de cruzar, al tiempo que ocupaban los alrededores inmediatos a la ciudad de Manila, es decir el Malecón, La Luneta, y los paseos de Aguadas e Isabel II. El segundo batallón de Oregón fue la primera fuerza que entró en Manila. Los 8.500 hombres aproximadamente que ocuparon la ciudad expulsaron de las escasas posiciones que habían tomado a los filipinos y no les permitieron entrar en la ciudad. La mayor parte de las fuerzas tagalas quedaron frente a las líneas defensivas españolas que nunca llegaron a romper.

La plaza fue ocupada y las tropas españolas desarmadas antes que la conferencia entre Jáudenes y los americanos hubiese terminado. Antes de que se llegase a un acuerdo en los términos de la capitulación la ciudad estaba tomada por la división de Anderson. No había posible marcha atrás.

32 Cuenta Sastron que un grupo de 300 infantes españoles, que se retiraban llevando seis cañones, bajo el mando del capitán Sendra y el teniente Mera, hallaron a unos americanos en su camino, los cuales les informaron que todo había terminado y que ya "todos éramos amigos". Procediendo los soldados norteamericanos a ayudar a estas fuerzas a portar a los numerosos heridos que llevaban en camillas. Sólo el día 13 de agosto las fuerzas españolas de Manila tuvieron 300 bajas (M. SASTRON, [16], p. 503). 
(...) hasta las 6 de la tarde se ha visto pasar por las calles de Manila diversos Cuerpos del ejército español que iban á dejar las armas en la fuerza de Santiago. A las seis la bandera española que coronaba esta fortaleza ha sido arriada, siendo izada en su lugar la bandera Yanqui. Los Yanquis que estaban en la fuerza han saludado la bandera con el grito de "urra", y una banda de música ha tocado el himno nacional delante de la bandera en el paseo entonces solitario de María Cristina (...).

Las trincheras de la parte de Binondo y Sta Mesa, continúan defendidas por nuestras tropas mandadas por el Gral. Monet y el Coronel Carbó. Hay por aquel lado mucho tiroteo y mañana abandonarán los nuestros aquellas posiciones para que las ocupen los yanquis si les viene en gusto.

Las bajas se calculan en 400 por nuestra parte, y 2.000 por la de los Yanquis. Es probable que estas cifras sean exageradas como de primera impresión (...). Al caer la tarde se ha embarcado con su familia para Hong Kong el General Augustin".

Los norteamericanos prepararon su ataque principal contra el fuerte de San Antonio Abad emplazando 30 piezas de artillería frente a nuestras posiciones, atrincherándose al sur de las líneas españolas, concentrando gran número de hombres frente a los blocaos 13 y 15. Con la recién llegada tercera expedición de fuerzas contaban con 12.000 hombres, pues la división de Anderson había desembarcado totalmente en Parañaque ${ }^{33}$. Para apoyar este ataque terrestre la escuadra se situó en la bahía frente a Parañaque: el «Charleston» junto con dos de los barcos españoles apresados por los americanos, «Callao» $\mathrm{y}$ «Manila». Otros barcos tomaron posiciones, uno de los cruceros que se situó frente al barrio de Tondo reforzado por

\footnotetext{
33 El 1 de agosto el mando americano estimó estar ya en condiciones de asaltar Manila. $\mathrm{Al}$ mando de 8.500 hombres de las fuerzas preparadas para el ataque estaba el general Merrit, formando una división que encomendó al general Anderson, compuesta de dos brigadas.

El mando de la primera se dio al general de brigada de voluntarios Arthur Mc-Arthur: Se componía de dos batallones del 23 de infantería; un batallón del 14; de los voluntarios de Minesota; de dos batallones del norte de Dakota; dos batallones del de Idaho; un batallón del regimiento de Wyoming, todos estos voluntarios, y la batería de Astor. La segunda brigada la mandaba el general de voluntarios F.V. Greene. Estaba formada por dos batallones del 18 de infantería; un batallón de artillería; una compañía de ingenieros y fuerzas de voluntarios de los regimientos de California, Colorado, Nebraska, Pensilvania y dos baterías de Utah.
}

R. I., $1998, \mathrm{n}^{\circ} 213$ 
un monitor, al tiempo que los cañoneros «Petrel» y «Concord» se alejaban de la boca del río Pasing para situarse a muy corta distancia de la escollera. El buque insignia «Olimpia» dirigía toda la operación desde el centro de la bahía.

El 13 de agosto las tropas españolas, en escaso número frente a sus sitiadores, mal alimentadas, dada la escasez de víveres, exhaustas por el prolongado asedio y lo duro de los combates se preparaban para rechazar el asalto final ${ }^{34}$. A las cinco y treinta de la mañana comenzaron los cañones americanos a realizar una preparación artillera sobre el casi demolido fortín de San Antonio Abad, iniciándose casi simultáneamente el fuego de fusilería por parte de las tropas americanas en el sector comprendido entre el mar y Maitubing. Para reforzar este punto tan comprometido destinó el mando a dos compañías de la columna volante de Dujiols, mandadas por el teniente coronel Hernández. El ataque, aunque muy duro, fue sólo un tanteo de las defensas españolas.

Tras dos horas de tensa calma, nuevos buques tomaron posiciones dando el «Olimpia» la orden de comenzar el bombardeo. El monitor «Monterrey» y los cañoneros «Petrel», «Raliegh» y «Callao» abrieron fuego con todas sus piezas sobre el fortín de Santiago Abad: las ya muy dañadas defensas saltaban por causa del intenso bombardeo naval, incendiándose varios de los parapetos y blocaos. Al poco la infantería y la artillería comenzaron a secundar el fuego de sus buques de guerra. Los disparos de una de las baterías de Utah destacó entre todas por su certero fuego.

Mientras esto ocurría, en la zona de Malate y San Fernando los tagalos atacaban con fuerza el flanco derecho de las defensas españolas. Merritt obtuvo de Aguinaldo que sus fuerzas se retirasen de las trincheras que habían construido frente al fuerte de San Antonio Abad, a unos 730 metros de las defensas españolas, ocupando así la brigada Greene un frente de unos $3.500 \mathrm{~m}$. que se extendía hacia el norte, justo enfrente de las líneas españolas; quedando, en este sector, los filipinos fuera del frente de combate, a retaguardia de las tropas de Merritt.

La brigada Greene fue reforzada por la de Mac-Arthur, convirtiendo ambas el fuego sobre las trincheras españolas en algo formi-

\footnotetext{
34 Pensemos que el asedio había durado 105 días, el doble que los famosos 55 días en Pekín, siendo los combates mil veces más numerosos y de una mayor dureza.
} 
dable, volviéndose nuestra situación en insostenible, a lo que se unió la total destrucción del fuerte de San Antonio Abad y de las trincheras que los circundaban, por la artillería del «Olimpia» y el «Monterrey».

El teniente coronel Hernández, jefe de estas fuerzas dio orden de retirarse, ya que la defensa era imposible. El general Arizmendi, que con su cuartel estaba en el puente de Paso, ordenó que Hernández tomase posiciones en la casi inexistente segunda línea de defensa con el objetivo de, al menos, ganar tiempo.

La retirada fue muy desorganizada, a pesar de los esfuerzos de jefes como Dujiols, Hernández, el coronel Victoria, o el propio general Arizmendi. Cuatro secciones de cazadores y una de marinería fueron copadas por los tagalos y capturadas. Una compañía aislada sostuvo la retirada hasta que las fuerzas llegaron a la iglesia del barrio de la Ermita. La retirada desordenada de las tropas de los blocaos 12,13 y 14 abrieron una brecha en la segunda línea de defensa que obligaron a un contraataque español a la bayoneta que logró por algún tiempo, recuperar algunas posiciones ya en manos americanas, lo que permitió la retirada de algunas fuerzas retrasadas. Al parecer, esta héroica acción de guerra fue llevada a cabo por un teniente procedente de la clase de tropa, D. Faustino Ovide González ${ }^{35}$.

A pesar de todo este esfuerzo cayeron en manos enemigas las tropas que defendían la Concordia y el fuerte de Santa Ana.

En el momento que las fuerzas que aún quedaban operativas en el sector se disponían a hacerse fuertes en las murallas de Manila, Arizmendi recibió orden de que cesasen las hostilidades y que acu-

\footnotetext{
35 Había llegado a Filipinas en 1895, ganado en la guerra de 1896/97 y en la del 98 cinco Cruces al Mérito Militar rojas y una de María Cristina, paso anterior a la Laureada. Durante el asedio tuvo encomendado el mando de uno de los blocaos. Fue herido en combate, logrando tomar al enemigo un cañón y una ametralladora. Como señala su descendiente, buen amigo y compañero Agustín R. RoDRíGUEZ GoNZÁLEZ en su libro La Guerra del 98: "El 13 de Agosto, y como la retirada en su sector fue precipitada y diera origen a confusión, se la mandó con su sección de 30 hombres a recuperar una trinchera abandonada poco antes, desde la que cubriría la retirada a las demás fuerzas. Al avanzar, la encontró ocupada por fuerzas americanas, sin embargo la tomó al asalto con fuertes bajas entre sus enemigos y la defendió hasta verse aislado, retrocediendo luego sin dejar de combatir, y pese a estar herido en la boca, hasta la inmediaciones de la ciudad, donde se le ordenó que cesara la resistencia, pues hacía ya tiempo que Manila había capitulado". por esta acción recibió la Gran Cruz de Carlos III.
}

R. I., 1998, n. $^{\circ} 213$ 
diese al convento de San Agustín, pues se habían iniciado las conversaciones para la rendición de la guarnición de Manila.

La aparición de una bandera blanca en el fuerte de San Diego, lugar en que se hallaba el General en Jefe español, llevó a Dewey, sobre la diez y media de la mañana, a ordenar a su escuadra que suspendiese el fuego. Inmediatamente tropas del regimiento de Colorado, de la brigada de Greene, cruzaron las trincheras españolas. La bandera española que aún ondeaba en el fortín de San Antonio Abad fue arriada por un soldado yanki, el cual izó una bandera de su nación.

Una vez pedido por Jáudenes el parlamentar, el coronel de E.M. Olaguer Feliú y el interprete Casademunt fueron al Malecón a recibir a dos jefes norteamericanos, el teniente coronel C.A. Whitier del ejército y al teniente Brumby de la marina. En el Ayuntamiento se entrevistaron con Jáudenes y con los generales Tejeiro y Arizmendi, almirante Montojo y auditor Peña. La entrevista duró cinco horas.

Las tropas españolas conocida la noticia de la rendición se dirigieron a sus respectivos acuartelamientos a la espera de órdenes. A pesar de esto, durante casi treinta horas, en algunas de las líneas exteriores tropas españolas siguieron luchando contra las fuerzas tagalas.

Domingo 14.

"Van llegando de las trincheras los cazadores que las defendian y son alojados en las Iglesias de la población que es el sitio en que primero han pensado las Autoridades Españolas una vez cedidos a los Yanquis todos los cuarteles".

\section{Lunes 15.}

"Las guardias Yanquis ocupan la ciudad en gran número. Su conducta con los indios ha variado mucho desde el día en que pusieron el pié en Cavite. Entonces con rostro muy risueño y ademanes cariñosos les decían á los indios: El español "malo". El indio "bueno". Ahora por cualquier niñería les dan á los indios con la culata en la cara, aunque sean Cabecillas. Hoy mismo por una quisicosa un fornido yanqui ha arrojado á un jovencito mestizo muy bien vestido y con gafas, del puente de España abajo. Afortunadamente la cosa no ha pasado de un sustazo y un remojón. Si se arma por la calle alguna reyerta entre un español y un indio al acercarse la policía yanqui, por descontado tiene toda la culpa el indio, el cual carga con 
ella y con algunas patadas y culatazos. En su afán de hacer justicia inmediatamente, han llegado los yanquis á disparar su revolver sobre algún indio en medio de la calle. Nunca las guardias españolas habían sabido tratar así á la gente. La guardia civil veterana compuesta de españoles é indígenas continúa prestando sus servicios como antes de la guerra. (...) Se ha sabido con general disgusto que se firmó un armisticio entre España y Estados-Unidos precisamente un día antes de ser entregada Manila".

\section{CONCLUSIÓN.}

Algunos investigadores han querido restar importancia a la resistencia de Manila. Durante algo más de tres meses una guarnición relativamente escasa, encargada de defender un perímetro inmenso, el cual estaba repleto de personal civil, y en la que buena parte de sus fuerzas estaban integradas por contingentes nativos de dudosa fidelidad y de civiles militarizados a toda prisa, resistió a los ataques de numerosísimas fuerzas nativas y de un gran contingente de tropas de una nación occidental.

Aducen, y es cierto, que las bajas españolas no fueron excesivamente numerosas como cabía de esperar en un largo asedio y dada la dureza de los combates, aunque tampoco podemos olvidar que aún nadie ha aportado una cifras exactas, contrastadas y fiables, tanto de los efectivos reales de los defensores, como de los muertos y heridos habidos entre ellos durante el asedio. Para rebatir éstas críticas recordemos que las tropas tagalas eran muy numerosas, pero deficientemente armadas, mal mandadas y carentes de verdadera eficacia, y que se enfrentaban a una fuerza europea curtida y atrincherada. La historia colonial nos ha dejado numerosos ejemplos de combates similares: ya en Blood River los boers atrincherados tras sus carromatos aniquilaron un inmenso ejército zulú sin bajas, y durante la guerra de los zulúes, la Cía. B del II Batallón del 24a Regimiento, el South Wales Borderers, con 139 hombres -de ellos 35 enfermos-, mandados por los teniente Chard, de ingenieros, y Bromhead, de infantería, resistieron el ataque de un impi zulú de 4.000 hombres durante casi doce horas de combate continuo. Tuvieron 15 muertos y 12 heridos, de éstos 2 morirían más tarde, frente a 371 muertos por parte zulú. El mismo año de 1898 los británicos se enfrentaban en

R. I., 1998, n. 213 
campo libre al ejército derviche en Omdurman, con 4 oficiales británicos muertos y 18 soldados frente a una bajas entre los seguidores de Mahdi estimadas en 10.000 muertos, 15.000 heridos y 5.000 prisioneros, siendo muchos de los heridos los que fallecieron luego. Las cifras hablan por si solas ${ }^{36}$.

En relación a los combates con las tropas yanquis, estas eran de muy mala calidad, aunque dotadas de material moderno, muy numerosas y lanzados al ataques sobre unas fuerzas muy desgastadas por lo largo del asedio, tras unos bombardeos navales y terrestres considerables y, sobre todo, carentes de toda esperanza. A pesar de todo, la toma de la ciudad se produjo, como tantas veces habían ocurrido en aquella guerra, aprovechando un alto el fuego para negociar, momento en que sus unidades entraron en torrente en Manila abusando de la protección que les prestaba la bandera de tregua.

Para finalizar no olvidemos señalar que cuando las tropas yanquis rompieron las líneas defensivas de Manila sus jefes ya sabían que los gobiernos de Washington y Madrid había firmado el armisticio y que ambas naciones negociaban la paz. La guerra terminó como había comenzado, ignorando los agresores todas la reglas de la guerra en una época en la que el honor y la caballerosidad eran todavía parte del patrimonio de los hombres, de los ejércitos y de la naciones.

La guerra en Filipinas estuvo marcada por hechos tan poco dignos de ser recordados como la cobarde actuación del almirante Montojo y la del general Monet, la criticable postura del obispo de Manila Nozadela y de los capitanes generales Primo de Rivera y, especialmente, Augustín, lo cual no debe enturbiar la héroica actuación de los jefes, oficiales, clases y tropas, y de la población Manila, durante aquellos largos tres meses en que la ciudad fue el bastión principal de lo que restaba de España en las Filipinas.

36 Vid. Christopher Wilkinson-Latham: The South Wales Borders, Berkshire (GB), Osprey, 1975; Ian KNIGHT y Ian CASTLE: Guerra Zulú 1879, Madrid, Ed. del Prado, 1995; Teniente Coronel F.E. Whitton; Rorker's Drift, Londres, Reliance Printing Works, 1979; Angus McBRIDE, The Zulu War, Berkshire, Osprey, 1976; Michael BARTHORP, War on the Nile, Londres, Blandford Press, 1984; Donald Featherstone, Omdurman 1898, Madrid, Ed. del Prado, 1995. 
There are two landmarks in the loss of philippines in 1898: the Cavite naval battle and the subsequent siege of Manila. Between May and August 1898 the Tagalo independentist forces under Aguinaldo, and the Northamerican soldiers under Commodore Dewey and General Merrit, laid siege to and took over the capital city of the Colony after a long and hard siege, full of struggles. A Jesuit's personal diary found in the Rome archives provides a day-by-day chronicle of the siege. By contrasting this information with other existing documentation it has been possible to reconstruct one of the historical keys to the understanding of Spain's defeat in the Pacific.

R. I., $1998, \mathrm{n}^{\circ} 213$ 